\title{
SIMPOL.1: a simple group contribution method for predicting vapor pressures and enthalpies of vaporization of multifunctional organic compounds
}

\author{
J. F. Pankow ${ }^{1}$ and W. E. Asher ${ }^{1,2}$ \\ ${ }^{1}$ Department of Environmental and Biomolecular Systems, OGI School of Science and Engineering, Oregon Health and \\ Science University, Beaverton, Oregon 97006-8921, USA \\ ${ }^{2}$ Air-Sea Interaction and Remote Sensing Department, Applied Physics Laboratory, University of Washington, Seattle, \\ Washington 98105, USA
}

Received: 3 July 2007 - Published in Atmos. Chem. Phys. Discuss.: 13 August 2007

Revised: 17 April 2008 - Accepted: 5 May 2008 - Published: 29 May 2008

\begin{abstract}
The SIMPOL.1 group contribution method is developed for predicting the liquid vapor pressure $p_{\mathrm{L}}^{\mathrm{o}}(\mathrm{atm})$ and enthalpy of vaporization $\Delta H_{\mathrm{vap}}\left(\mathrm{kJ} \mathrm{mol}^{-1}\right)$ of organic compounds as functions of temperature $(T)$. For each compound $i$, the method assumes $\log _{10} p_{\mathrm{L}, i}^{\mathrm{o}}(T)=\sum_{k} v_{k, i} b_{k}(T)$ where $v_{k, i}$ is the number of groups of type $k$, and $b_{k}(T)$ is the contribution to $\log _{10} p_{\mathrm{L}, i}^{\mathrm{o}}(T)$ by each group of type $k$. A zeroeth group is included that uses $b_{0}(T)$ with $\nu_{0, i}=1$ for all $i$. A total of 30 structural groups are considered: molecular carbon, alkyl hydroxyl, aromatic hydroxyl, alkyl ether, alkyl ring ether, aromatic ether, aldehyde, ketone, carboxylic acid, ester, nitrate, nitro, alkyl amine (primary, secondary, and tertiary), aromatic amine, amide (primary, secondary, and tertiary), peroxide, hydroperoxide, peroxy acid, $\mathrm{C}=\mathrm{C}$, carbonylperoxynitrate, nitro-phenol, nitro-ester, aromatic rings, non-aromatic rings, $\mathrm{C}=\mathrm{C}-\mathrm{C}=\mathrm{O}$ in a nonaromatic ring, and carbon on the acid-side of an amide. The $T$ dependence in each of the $b_{k}(T)$ is assumed to follow $b(T)=B_{1} / T+B_{2}+B_{3} T+B_{4} \ln T$. Values of the $B$ coefficients are fit using an initial basis set of 272 compounds for which experimentally based functions $p_{\mathrm{L}, i}^{\mathrm{o}}=f_{i}(T)$ are available. The range of vapor pressure considered spans fourteen orders of magnitude. The ability of the initially fitted $B$ coefficients to predict $p_{\mathrm{L}}^{\mathrm{o}}$ values is examined using a test set of 184 compounds and a $T$ range that is as wide as 273.15 to $393.15 \mathrm{~K}$ for some compounds. $\sigma_{\text {FIT }}$ is defined as the average over all points of the absolute value of the difference between
\end{abstract}

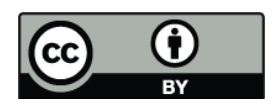

Correspondence to: J. F Pankow (pankow@ebs.ogi.edu) experimental and predicted values of $\log _{10} p_{\mathrm{L}, i}^{\mathrm{o}}(T)$. After consideration of $\sigma_{\text {FIT }}$ for the test set, the initial basis set and test set compounds are combined, and the $B$ coefficients reoptimized. For all compounds and temperatures, $\sigma_{\mathrm{FIT}}=0.34$ : on average, $p_{\mathrm{L}, i}^{\mathrm{o}}(T)$ values are predicted to within a factor of 2. Because $d\left(\log _{10} p_{\mathrm{L}, i}^{\mathrm{o}}(T)\right) / d(1 / T)$ is related to the enthalpy of vaporization $\Delta H_{\mathrm{vap}, i}$, the fitted $B$ provide predictions of $\Delta H_{\mathrm{vap}, i}$ based on structure.

\section{Introduction}

For organic compound $i$, knowledge of the liquid vapor pressure $p_{\mathrm{L}, i}^{\mathrm{o}}$ at the system temperature $(T)$ is required whenever phase equilibrium of $i$ between a liquid phase and the gas phase is of interest. This type of partitioning arises frequently in many disciplines, and so the need for reliable $p_{\mathrm{L}, i}^{\mathrm{o}}$ values is considerable. And, since the $T$ dependence of $p_{\mathrm{L}, i}^{\mathrm{o}, i}$ is determined by the compound-dependent enthalpy of vaporization $\Delta H_{\mathrm{vap}, i}$, the same need extends to $\Delta H_{\mathrm{vap}, i}$ values. In our case, the topic of interest is gas/particle partitioning in atmospheric and smoke aerosol systems (e.g., Pankow, 1994a, 1994b, 2001, 2003; Pankow et al., 2001, 2003, 2004; Barsanti and Pankow, 2004, 2005, 2006).

Given the infinite structural variety possible with organic compounds, laboratory measurements will never keep pace with the need for new $p_{\mathrm{L}, i}^{\mathrm{o}}$ information. Consequently, there is continuing interest in the development of reliable methods for predicting $p_{\mathrm{L}, i}^{\mathrm{o}}$ and $\Delta H_{\mathrm{vap}, i}$ values. In the case of the behavior and formation of organic particulate matter (OPM) in the atmosphere, there is growing interest in a

Published by Copernicus Publications on behalf of the European Geosciences Union. 
Table 1a. Non-oxygenated, hydroxyl, ketones, aldehydes, and carboxylic acid saturated compounds in the basis set for the initial fit.

\begin{tabular}{lll}
\hline $\begin{array}{l}\text { Nonoxygenated alkanes } \\
\text { 2,2-dimethyl pentane }\end{array}$ & $\begin{array}{l}\text { Alkanoic ketones and aldehydes } \\
\text { butanal }\end{array}$ & $\begin{array}{l}\text { Alkanoic carboxylic acids } \\
\text { ethanoic acid }\end{array}$ \\
1,1-dimethyl cyclohexane & 2-methyl propanal & propanoic acid \\
cis-1,2-dimethyl-cyclohexane & cylopentanone & 2-methyl-propanoic acid \\
2,2,4 trimethyl pentane & cylohexanone & butanoic acid \\
& 5-methyl-2-hexanone & cyclobutanoic acid \\
Alkanoic hydroxyls & octanal & 3-methyl butanoic acid \\
cyclobutanol & 2-octanone & pentanoic acid \\
2-butanol & 3-hydroxy-3-methyl-2-butanone & cyclopentane carboxylic acid \\
2-methyl-1-propanol & 4-hydroxy-2-pentanone & hexanoic acid \\
1-butanol & 2,4 hexanedione & 2-ethyl-butanoic acid \\
1-pentanol & 4-hydroxy-4-methyl-2-pentanone & 4-methyl-pentanoic acid \\
2,2-dimethyl-1-propanol & 3-hexanone & cyclohexanecarboxylic acid \\
2-pentanol & hexanal & heptanoic acid \\
cyclohexanol & heptanal & octanoic acid \\
1-hexanol & 2-heptanone & nonanoic acid \\
2-methyl 2-pentanol & & 2-oxo-propanoic acid \\
2,3 dimethyl 2-butanol & & 2-hydroxy-propanoic acid \\
3-hexanol & & 4-oxo-pentanoic acid \\
1,2-propanediol & & butanedioic acid \\
1,4-butanediol & & pentanedioic acid \\
2,3-butanediol & & \\
1,3-butanediol & & \\
1,2-butanediol & & \\
1,5-pentanediol & & \\
2,3-pentanediol & & \\
1,2-pentanediol & & \\
2,4-dimethyl-cyclopentanol & & \\
cycloheptanol & & \\
2-methyl-cis-cyclohexanol & & \\
\hline & & \\
& & \\
& & \\
& & \\
& & \\
& &
\end{tabular}

wide range of multi-functional oxygenated compounds and nitrogen-containing compounds, e.g., hydroxy acids, diacids, hydroxy diacids, hydroxy aldehydes, organic nitrates, nitro aldehydes, etc.

Quantum-mechanical calculations are making steady progress in the theater of predicting $p_{\mathrm{L}, i}^{\mathrm{o}}$ values for any structure of interest (Diedenhofen et al., 2007; Verevkin et al., 2007; Banerjee et al., 2006; Tong et al., 2004). However, prediction efforts for more complicated structures can now only be based on either a complex consideration of the interaction forces between molecules (i.e., dispersion, induction, dipole and H-bonding) as in the SPARC model discussed by Hilal et al. (1994), or by empirical group-contribution means.

In the group contribution approach to prediction of molecular properties, it is hypothesized that the value of a property of interest for compound $i$ can be predicted based on empirically determinable contributions from the structural fragments that comprise $i$. As a function of temperature $T$, the result is often an equation of the type

$$
\log _{10} Z_{i}(T)=b_{0}(T)+\sum_{k} v_{k, i} b_{k}(T)
$$

where: $Z_{i}(T)$ is the property of interest, e.g., $p_{\mathrm{L}, i}^{\mathrm{o}}(T)$; the parameter $b_{0}(T)$ is a $T$-dependent constant; $v_{k, i}$ is the number of groups of type $k$ in $i$; the index $k$ may take on the values 1,2,3, etc.; and $b_{k}(T)$ is the group contribution term for group $k$. Values for $b_{0}(T)$ and the set of $b_{k}(T)$ are usually determined by fitting (i.e., optimizing) Eq. (1) using laboratory-based measures of $Z_{i}(T)$ for a large number of compounds that contain the groups of interest. For example, for both 2,3- and 2,4-dihydroxypentane it can be considered that $\nu_{\mathrm{OH}, i}=2, v_{\mathrm{CH}_{3}, i}=2, \nu_{\mathrm{CH}_{2}, i}=1$, and $\nu_{\mathrm{CH}, i}=2$. In this approach, four $b_{k}(T)$ values are required, and Eq. (1) will give the same prediction for $Z_{i}(T)$ for both isomers. However, the vicinal nature of the two $\mathrm{OH}$ groups in 2,3dihydroxypentane allows greater intramolecular interaction of the $\mathrm{OH}$ groups (and less intermolecular interaction) than in the 2,4 isomer, causing differences in molecular properties. In the case of vapor pressure, $p_{\mathrm{L}, i}^{\mathrm{o}}(T)$ will be higher for the 2,3 isomer than for the 2,4 isomer. Accounting for such property differences among isomers can be accomplished by consideration of additional, "higher-order" groups. Thus, for 2,3-dihydroxypentane a "second-order" 
Table 1b. Continued.

\begin{tabular}{|c|c|c|}
\hline \multicolumn{2}{|l|}{ Nonoxygenated alkanes } & \multirow{2}{*}{$\begin{array}{l}\text { Nonoxygenated aromatics } \\
\text { (1,1-dimethyl-ethyl)-benzene } \\
\text { 1,2-diphenyl-ethane }\end{array}$} \\
\hline 2,3-dimethyl-2-butene & & \\
\hline Alkenoic hydroxyls & & 2-phenyl-propane \\
\hline 3-buten-1-ol & 2-methyl-4-penten-2-ol & \\
\hline 3-buten-2-ol & 3-cyclohexen-1-ol & Phenyl alkanoic hydroxyls \\
\hline 2-methyl-2-buten-1-ol & 3-methyl-3-penten-2-ol & 1-phenyl-ethanol \\
\hline 2-penten-1-ol & 4-methyl-3-penten-1-ol & 2-phenyl-ethanol \\
\hline 3-methyl-3-buten-1-ol & cyclohex-1-enyl-methanol & \\
\hline 3-penten-1-ol & 3-methyl-2-cyclohexen-1-ol & Phenols \\
\hline 2,3-dimethyl-2-buten-1-ol & cis-9-octadecen-1-ol & phenol \\
\hline 2-methyl-1-penten-3-ol & & 2-hydroxy-1-methyl-benzene \\
\hline Alkenoic ketones and aldehydes & & 3-hydroxy-1-methyl-benzene \\
\hline 2-butenal & 4-methyl-3-penten-2-one & 4-hydroxy-1-methyl-benzene \\
\hline 3-buten-2-one & 4-methyl-4-penten-2-one & 2-ethyl-phenol \\
\hline 2-methyl-2-butenal & 5-hexen-2-one & Aromatic ketones and aldehydes \\
\hline 3-penten-2-one & 5-hexen-3-one & benzaldehyde \\
\hline 2,3-dimethyl-2-butenal & 1-cyclohex-1-enyl-ethanone & 1-phenyl-ethanone \\
\hline 2,4-hexadienal & 3-methyl-3-penten-2-one & 2-methyl-benzaldehyde \\
\hline 5-(1-hydroxy-1-methyl-ethyl)-2-methyl-cyclohex-2-enone & & $\begin{array}{l}\text { 2-phenyl-propanal } \\
\text { 1-(2-methyl-phenyl)-ethanone }\end{array}$ \\
\hline Alkenoic carboxylic acids & & 1-phenyl-2-propanone \\
\hline propenoic-acid & 3-hexenoic-acid & Aromatic carboxylic acids \\
\hline 2-methyl-propenoic-acid & 4-hexenoic-acid & 3-methyl-benzoic acid \\
\hline 3-butenoic-acid & 2-cyclohexene carboxylic acid & 4-methyl-benzoic acid \\
\hline 2-ethyl-propenoic-acid & 9,12 -octadecadienoic acid & 2-phenyl-ethanoic acid \\
\hline 2-pentenoic-acid & $9,12,15$-octadecatrienoic acid & 2-phenyl-propanoic acid \\
\hline 2-cyclopentene-carboxylic-acid & & trans-3-phenyl-2-propenoic acid \\
\hline
\end{tabular}

group $\mathrm{CH}(\mathrm{OH})-\mathrm{CH}(\mathrm{OH})$ (="vicinal-OH") can be invoked with $v_{\text {vicinal }-\mathrm{OH}, i}=1$. Kolská et al. (2005) describe a thirdorder method for prediction of $\Delta H_{\mathrm{vap}, i}$ and the entropy of vaporization $\Delta S_{\mathrm{vap}, i}$ values at $298.15 \mathrm{~K}$.

In the most general application of a group contribution model, the fitting takes place over a broad range of compound types, e.g., simple alkanes, functionalized alkanes, aromatics, functionalized aromatics, etc. In that case, $b_{0}(T)$ serves as a general fitting constant. Alternatively, the fitting can take place within a particular class of compounds, as in the study by Lee et al. (2000) of substituted benzene compounds wherein for predicting $p_{\mathrm{L}, i}^{\mathrm{o}}(298.15)$ the value of $b_{0}(298.15)$ was not obtained from the fitting process. Rather, it was defined that $b_{0}(298.15)=\log _{10} p_{\mathrm{L} \text {, benzene }}^{\mathrm{o}}(298.15)$. A secondorder group contribution model was then fit to

$\log _{10} p_{\mathrm{L}, i}^{\mathrm{o}}(298.15)=\log _{10} p_{\mathrm{L}, \text { benzene }}^{\mathrm{o}}(298.15)+$

$\sum_{k} v_{k, i} b_{k}(298.15)$

The summation accounts for how the presence of the various first- and second-order groups cause $p_{\mathrm{L}, i}^{\mathrm{o}}(298.15)$ to differ from $p_{\mathrm{L} \text {, benzene }}^{\mathrm{o}}(298.15)$.
In a generalization (though first order) of the Lee et al. (2000) approach, Capouet and Müller (2006) allowed that a range of parent structures would be of interest, and so existing $p_{\mathrm{L}, i}^{\mathrm{o}}(T)$ data for a range of compounds were fit to

$\log _{10} p_{\mathrm{L}, i}^{\mathrm{o}}(T)=\log _{10} p_{\mathrm{L}, \mathrm{hc}-i}^{\mathrm{o}}(T)+\sum_{k} v_{k, i} \tau_{k}(T)$

where $p_{\mathrm{L}, \mathrm{hc}-i}^{\mathrm{o}}(T)$ is the known vapor pressure for the nonfunctionalized hydrocarbon (hc) compound that possesses the skeletal structure underlying compound $i$, and the $\tau_{k}(T)$ are conceptually equivalent to the $b_{k}(T)$. Application of Eq. (3) to a particular $i$ requires knowledge (or an independent prediction) of $p_{\mathrm{L}, \mathrm{hc}-i}^{\mathrm{o}}(T)$; the summation accounts for how the substituents in $i$ cause $p_{\mathrm{L}, i}^{\mathrm{o}}(T)$ to differ from $p_{\mathrm{L}, \mathrm{hc}-i}^{\mathrm{o}}(T)$. In the fitting carried out by Capouet and Müller (2006), multiple different hc- $i$ structures were considered; the corresponding $p_{\mathrm{L}, \mathrm{hc}-i}^{\mathrm{o}}(T)$ and $p_{\mathrm{L}, i}^{\mathrm{o}}(T)$ were taken as the inputs, and the output was a set of $\tau_{k}(T)$ encompassing 10 groups: $\mathrm{OH}$ (as bonded to a primary, secondary, and tertiary carbon); $\mathrm{C}=\mathrm{O}$ (aldehyde or ketone); $\mathrm{COOH}$; hydroperoxy; nitrate (primary, secondary, and tertiary); and peroxyacetylnitrate (PAN). 
Table 1c. Amides, amines, ethers, and nitrate-group containing compounds in the basis set for the initial fit.

\begin{tabular}{|c|c|c|c|}
\hline Amides & & Ethers & \\
\hline formamide & dimethyl-propionamide & 1,2-epoxy-3-isopropoxy-propane & 1,3-dioxacyclooctane \\
\hline acetamide & diethyl-formamide & 1-butoxy-2-ethoxyethane & 1,4-dioxane \\
\hline methyl-formamide & butyl-acetamide & 2,6-dimethoxybenzoic acid & 1,3-dioxane \\
\hline dimethyl-formamide & propanamide & 1-(2-methoxyethoxy)-butane & 1,1-dimethoxyethene \\
\hline methyl-acetamide & butyramide & 3,4-dimethoxybenzoic acid & 1,2-dipropoxyethane \\
\hline ethyl-formamide & pentanamide & 4-methoxy-benzaldehyde & 1,3-diethoxypropane \\
\hline dimethyl-acetamide & hexanamide & $\begin{array}{l}\text { 2-(2-methylpropoxy)-ethanol } \\
\text { 3,5-dimethoxybenzoic acid }\end{array}$ & $\begin{array}{l}\text { 1,1-dimethoxybutane } \\
\text { levoglucosan }\end{array}$ \\
\hline Amines & & 3-(2-methoxyphenyl)-propionic acid & 2-n-butoxy-1-ethanol \\
\hline 2-propylamine & 4-amino-3-methylbenzoic acid & 3-(3,4-dimethoxyphenyl)-propionic acid & methoxyethane \\
\hline 1-propylamine & $n$-methyl-n-phenyl-amine & 5,5-dimethyl-1,3-dioxane & 4-methoxy-phenol \\
\hline phenylamine & dimethyl-hydroxylamine & 4,4-dimethyl-1,3-dioxane & 1,1-dimethoxy-2-butene \\
\hline 1-pentylamine & 1,2 ,-ethane-diamine & 2-methoxy-tetrahydropyran & \\
\hline 4-amino-toluene & 3-amino-4-methylbenzoic & 3-(4-methoxyphenyl)-propionic acid & \\
\hline 3-amino-toluene & 2-methyl-propylamine & cis-2,4-dimethyl-1,3-dioxane & \\
\hline 2-amino-toluene & 1-methyl-propylamine & & \\
\hline dimethylamine & 1-(dimethylamino)-2-propanone & Nitrates & \\
\hline 2-butylamine & (1-methyl-ethyl)-methylamine & 3-methylbutyl nitrate & \\
\hline methylamine & $n$-methyl-phenylamine & 2-methylpropyl nitrate & \\
\hline ethylamine & $n$-methyl-1-butanamine & butyl nitrate & \\
\hline trimethylamine & $n, n$-dimethyl- $n$-phenyl-amine & ethyl nitrate & \\
\hline diethylamine & triethylamine & propylnitrate & \\
\hline \multirow[t]{3}{*}{ 1-butylamine } & & 1-methylethyl nitrate & \\
\hline & & 1,2,3-propanetrinitrate & \\
\hline & & cyclopentyl nitrate & \\
\hline
\end{tabular}

Table 1d. Esters and nitro-group containing compounds in the basis set for the initial fit.

\begin{tabular}{llll}
\hline Esters & & Nitro-containing & \\
2-methyl-propyl ethanoate & ethyl 2-butoxy-ethanoate & 6-methyl-2,4-dinitrophenol & 3-nitro-2-pentanol \\
methyl 3-methyl-butanoate & ethyl 2-propoxy-ethanoate & 3-nitro-2-butanol & 2-methyl-3-nitrobenzoic \\
methyl pentanoate & diethyl hexandioanate & 1-nitrobutane & 3-methyl-2-nitrophenol \\
ethyl 2-methyl-propanoate & ethyl butanoate & 2-nitrobutane & 4-methyl-2-nitrophenol \\
ethyl hexanoate & phenyl-methyl ethanoate & ethyl 2-nitropropionate & 5-methyl-2-nitrophenol \\
hexyl ethanoate & diethyl ethanedioate & methyl 4-nitrobutanoate & 4-methoxy-2-nitrophenol \\
2-methyl-propyl butanoate & methyl cyclopropanoate & 1-nitromethyl-1-cyclohexanol & 2-nitro-ethanol \\
methyl heptanoate & ethyl cyclopropanoate & 4-(1-methylpropyl)-2-nitrophenol & 4-formyl-2-nitrophenol \\
dibutanoate ethane & propyl pentanoate & 2-nitro-1-propanol & 4-methyl-3-nitrobenzoic \\
1-methyl-propyl butanoate & methyl cyclobutanoate & 3-nitro-1-propanol & 5-methyl-2-nitrobenzoic \\
propyl 3-methyl-butanoate & ethyl cyclobutanoate & 3-methoxy-2-nitrobenzoic & 3-nitro-2-butanone \\
1-methyl-ethyl pentanoate & ethyl cyclopentanoate & 4-methoxy-3-nitrobenzoic & ethyl nitroacetate \\
diethyl cyclopropane-1,1-dicarboxylate & dimethyl 1,2-benzenedicarboxylate & 3-methoxy-4-nitrobenzoic & methyl nitroacetate \\
ethyl 4-methyl-pentanoate & dimethyl 1,3-benzenedicarboxylate & methyl-2-nitropropionate & 2-nitrobenzoic acid \\
2-methyl-propyl 2-methyl-propanoate & dimethyl cis-1,3-cyclohexanedicarboxylate & 2,4,6-trinitrotoluene & 3-nitrobenzoic acid \\
& & 2-nitrophenol & 4-nitrobenzoic acid \\
\hline
\end{tabular}

The use of $p_{\mathrm{L}, \mathrm{hc}-i}^{\mathrm{o}}(T)$ in Eq. (3) carries accuracy advantages for predicting $p_{\mathrm{L}, i}^{\mathrm{o}}(T)$ values because each prediction utilizes important specific knowledge of the vapor pressure of the compound with the underlying hc- $i$ structure. It is not surprising, then, that Capouet and Müller (2006) report generally better prediction accuracies for the Eq. (3) method than with the more general UNIFAC- $p_{\mathrm{L}}^{\mathrm{o}}$ method of Asher et al. (2002), though the fitting constants in Asher et al. (2002) have been superseded by those given in Asher and Pankow (2006). In any case, as a practical matter, requiring knowledge of $p_{\mathrm{L}, \mathrm{hc}-i}^{\mathrm{o}}(T)$ can be a significant disadvantage relative to a more general method that can be executed 
Table 1e. Peroxide, hydroperoxide, and carbonylperoxynitrate-group containing compounds in the basis set for the initial fit.

\begin{tabular}{ll}
\hline $\begin{array}{l}\text { Peroxides } \\
\text { di- } n \text {-butyl peroxide } \\
\text { di-(1,1-dimethylethyl)-peroxide } \\
\text { diethyl-peroxide }\end{array}$ & $\begin{array}{l}\text { Carbonylperoxynitrates } \\
\text { peroxyacetylnitrate }\end{array}$ \\
\hline $\begin{array}{l}\text { Hydroperoxides } \\
\text { 1-methyl-1-phenyl-ethyl-hydroperoxide } \\
\text { methyl-hydroperoxide }\end{array}$ & $\begin{array}{l}\text { Peroxyacids } \\
\text { 1-oxo-ethyl-hydroperoxide } \\
\text { (1,1-dimethylethyl)-hydroperoxide }\end{array}$ \\
\hline
\end{tabular}

Table 2. Average standard errors for the initial fit for all compounds in the basis set, and by compound class.

\begin{tabular}{lllr}
\hline Compound class & $\begin{array}{l}\text { number of compounds } \\
N_{\mathrm{c}}\end{array}$ & $\begin{array}{l}\text { average absolute error } \\
\sigma_{\text {FIT }} \log (\mathrm{atm})\end{array}$ & $\begin{array}{r}\text { average signed error } \\
\sigma_{\text {SGN }} \log (\operatorname{atm})\end{array}$ \\
\hline All compounds & 272 & 0.29 & $-1.4 \times 10^{-3}$ \\
Alkenes & 40 & 0.27 & $-7.0 \times 10^{-3}$ \\
Amides & 14 & 0.30 & $3.6 \times 10^{-3}$ \\
Amines & 27 & 0.24 & $-1.8 \times 10^{-2}$ \\
Aromatics & 21 & 0.22 & $6.2 \times 10^{-2}$ \\
Carbonylperoxynitrates & 1 & 0.21 & $-1.2 \times 10^{-2}$ \\
Esters & 30 & 0.24 & $3.0 \times 10^{-2}$ \\
Ethers & 27 & 0.21 & $-7.1 \times 10^{-2}$ \\
Hydroperoxides & 4 & 0.20 & $1.7 \times 10^{-3}$ \\
Nitrates & 8 & 0.14 & $3.2 \times 10^{-2}$ \\
Nitro-containing & 32 & 0.41 & $6.7 \times 10^{-2}$ \\
Peroxides & 3 & 0.50 & $2.8 \times 10^{-2}$ \\
Peroxyacids & 3 & 0.18 & $-1.1 \times 10^{-3}$ \\
Saturated & 62 & 0.38 & $-4.0 \times 10^{-2}$ \\
\hline
\end{tabular}

using fitting constants alone, e.g. the method of Asher and Pankow (2006) or that of Makar (2001). Moreover, for the compounds that actually form OPM in the atmosphere, good knowledge of the underlying structures is lacking, the available information being limited to a general idea of structural characteristics such as the number of carbons, the likely number and types of functional groups, and whether any aromatic or non-aromatic rings are likely to be present. The goal of this work was to develop a simple $p_{\mathrm{L}, i}^{\mathrm{o}}(T)$ group contribution method for which that level of information would be sufficient.

\section{Simplified $p_{\mathrm{L}}^{\mathrm{o}}$ prediction method (SIMPOL.1)}

\subsection{General}

The groups of interest considered include a range of firstorder group functionalities important for organic compounds involved in OPM formation, and several second order groups. Nevertheless, the total number of groups $N_{\mathrm{G}}$ was kept as small as possible while still affording good accuracy of the overall fit: SIMPOL. 1 is not intended as a method that employs many second- and third-order groups.

The SIMPOL.1 method is based on

$$
\log _{10} p_{\mathrm{L}, i}^{\mathrm{o}}(T)=b_{0}(T)+\sum_{k} v_{k, i} b_{k}(T) \mathrm{k}=1,2,3, \ldots
$$

wherein the role of $b_{0}(T)$ is the same as in Eq. (1), and the index $k$ may take on the values $1,2,3$, etc. The units carried by $p_{\mathrm{L}, i}^{\mathrm{o}}(T)$ are atm. The form of Eq. (4) is equivalent to

$$
\log _{10} p_{\mathrm{L}, i}^{\mathrm{o}}(T)=v_{0, i} b_{0}(T)+\sum_{k} v_{k, i} b_{k}(T) k=1,2,3 \ldots
$$

so that $b_{0}(T)$ can be viewed as pertaining to group "zero", with $v_{0, i} \equiv 1$ for all $i$. Thus, Eqs. (4) and (5) are equivalent to

$$
\log _{10} p_{\mathrm{L}, i}^{\mathrm{o}}(T)=\sum_{k} v_{k, i} b_{k}(T) k=0,1,2,3 \ldots
$$

wherein $k$ may take on the values $0,1,2,3$, etc., and for $k=0$, $v_{0, i} \equiv 1$ for all $i$. 


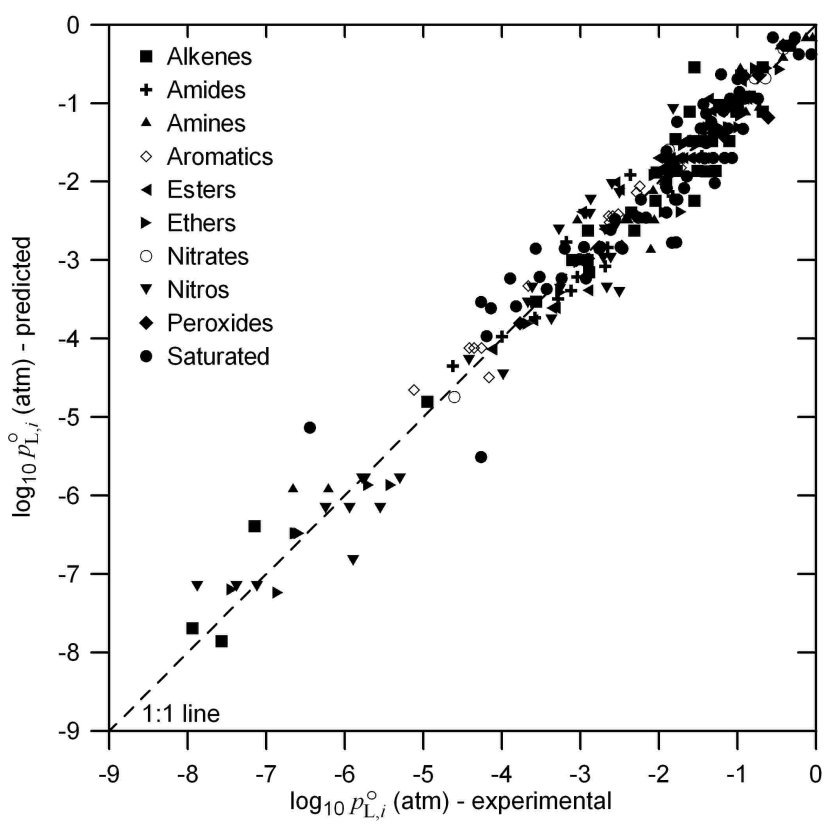

Fig. 1. Predicted vs. experimentally derived $p_{\mathrm{L}, i}^{\mathrm{o}}$ at $T=333.15 \mathrm{~K}$ for compounds in the initial basis set.

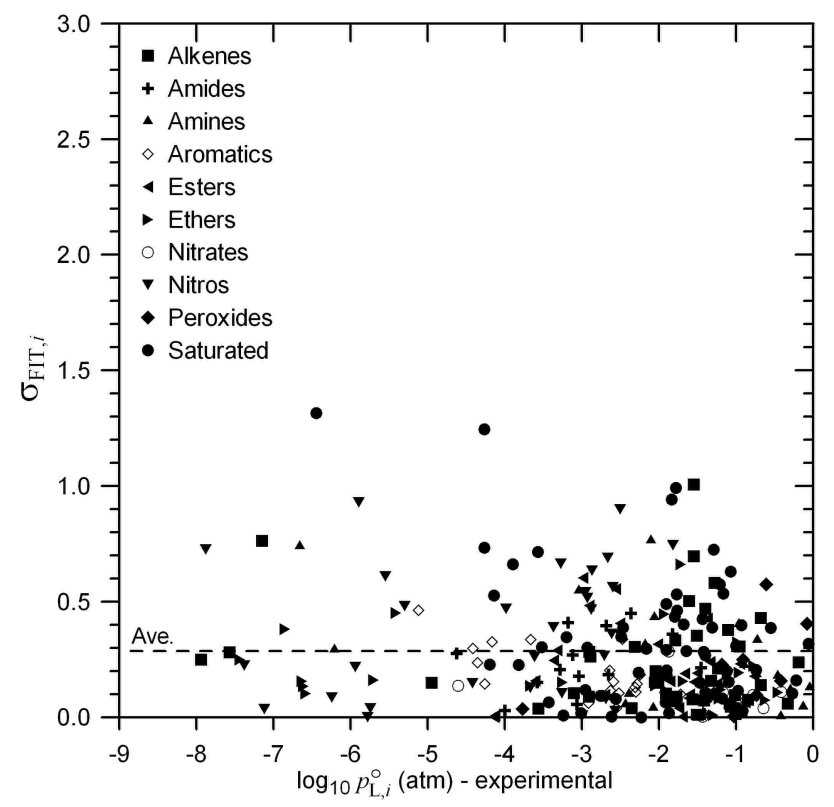

Fig. 2. $\sigma_{\mathrm{FIT}, i}$ at $333.15 \mathrm{~K}$ for the initial basis set compounds calculated as defined in Eq. (13) plotted vs. the experimentally derived $\log _{10} p_{\mathrm{L}, i}^{\mathrm{o}}(333.15)$.

Perhaps the most important chemical group in SIMPOL.1 is molecular carbon, for which $k=1$. Thus, $v_{1, i}$ denotes the number of carbon atoms in $i$, and $b_{1}(T)$ denotes the percarbon group contribution to $\log _{10} p_{\mathrm{L}, i}^{\mathrm{o}}(T)$. At ambient temperatures, $b_{1}(T) \approx-0.5$ (see Table 6 below) and so within any given compound class, $p_{\mathrm{L}, i}^{\mathrm{o}}(T)$ drops by about $1 / 3$ of

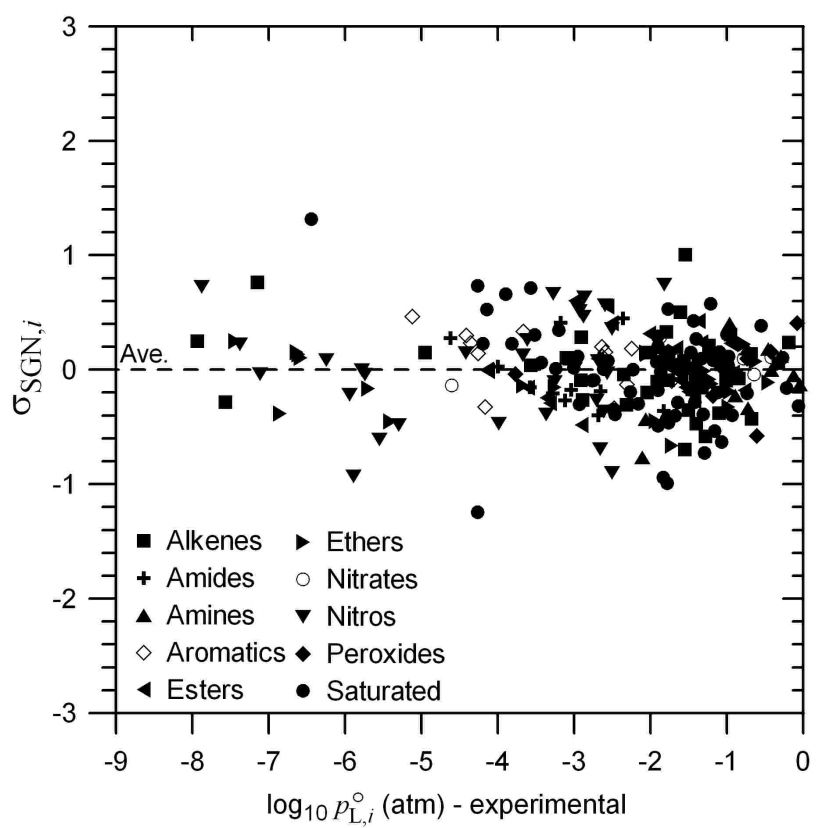

Fig. 3. $\sigma_{\mathrm{SGN}, i}$ at $333.15 \mathrm{~K}$ for the initial basis set compounds calculated as defined in Eq. (14) plotted vs. experimentally derived $\log _{10} p_{\mathrm{L}, i}^{\mathrm{o}}(333.15)$.

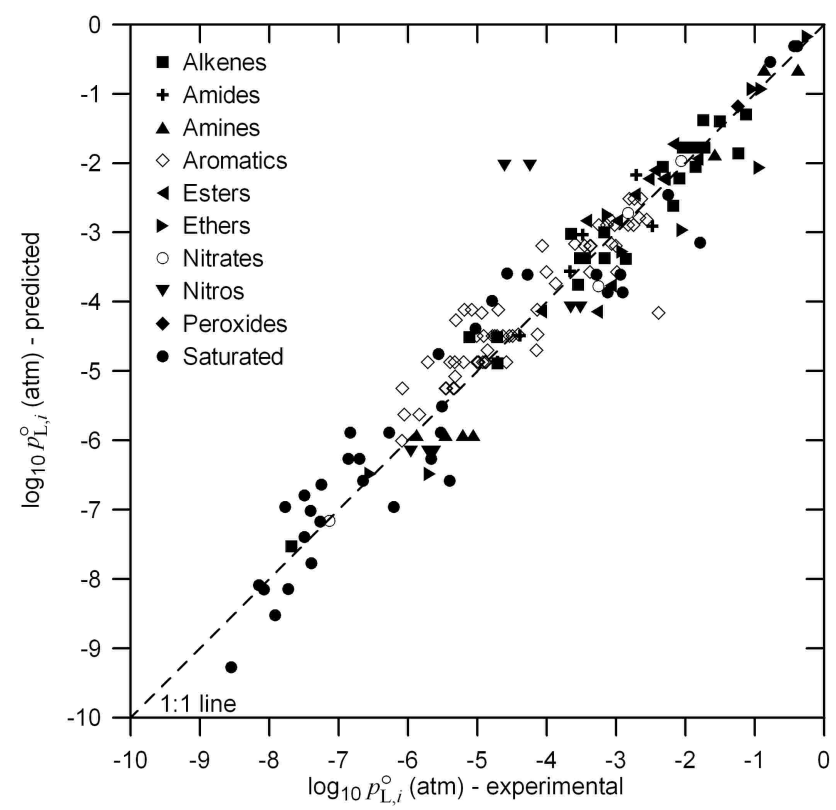

Fig. 4. Predicted vs. experimentally derived $p_{\mathrm{L}, i}^{\mathrm{o}}$ at $T=333.15 \mathrm{~K}$ for compounds in the test set. Predicted values are based on the optimization using the initial basis set compounds.

an order of magnitude for every unit increase in the carbon number.

By way of comparison with prior work from our group, Asher and Pankow (2006) follow Jensen et al. (1981) and 


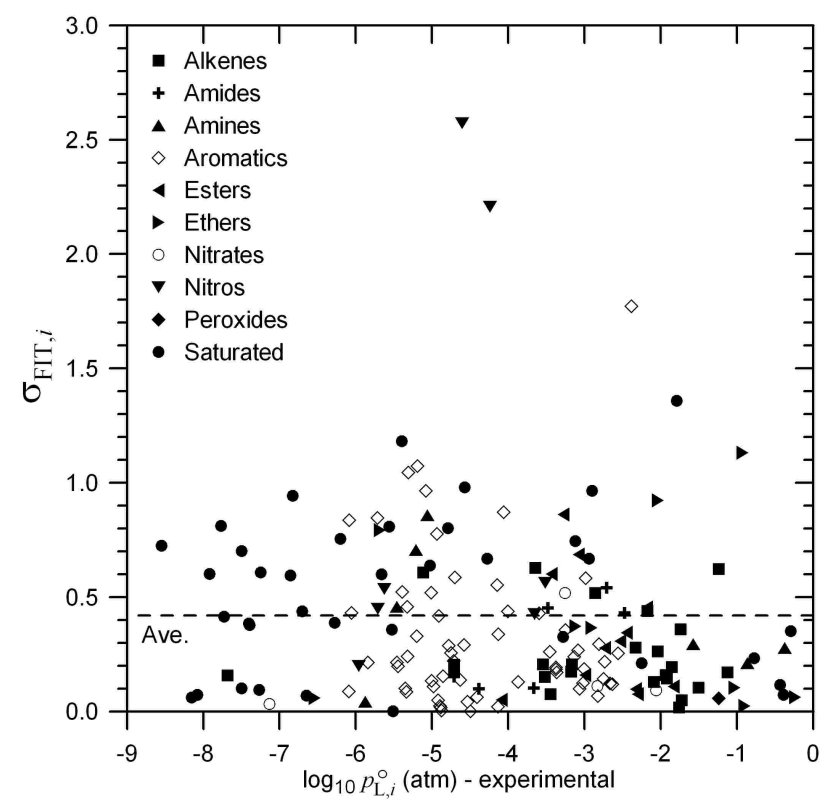

Fig. 5. $\sigma_{\mathrm{FIT}, i}$ at $333.15 \mathrm{~K}$ for the test set compounds calculated as defined in Eq. (13) plotted vs. experimentally derived $\log _{10} p_{\mathrm{L}, i}^{\mathrm{o}}(333.15)$. Predicted $p_{\mathrm{L}, i}^{\mathrm{o}}$ values used in calculating the $\sigma_{\mathrm{FIT}, i}$ are based on the optimization using the initial basis set compounds.

begin with

$$
\log _{10} p_{\mathrm{L}, i}^{\mathrm{o}}(T)=\sum_{k} v_{k, i}\left[\log _{10}\left(\Gamma_{k, i}\right)+\frac{\Delta g_{k}(T)}{2.303 R T}\right]
$$

where: each $\log _{10}\left(\Gamma_{k, i}\right)$ is a UNIFAC "residual term" that accounts for the intramolecule and intermolecular group-group interactions involving group $k ; R$ is the gas constant; and $\Delta g_{k}(T)$ is the difference between the molar free energy of group $k$ in the pure liquid state and in the perfect gas at 1 atm. After using tabulated values of UNIFAC group interactions parameters compiled in Hansen et al. (1991) to compute $\sum_{k} v_{k, i} \log _{10}\left(\Gamma_{k, i}\right)$ for the compounds in their basis set, Asher and Pankow (2006) fit $p_{\mathrm{L}, i}^{\mathrm{o}}(T)$ data values to Eq. (7) to obtain expressions for $\Delta g_{k}(T)$; a total of 24 groups were considered. Adoption of Eq. (6) in place of Eq. (7) amounts to assuming that each $b_{k}(T)$ can be fit as a lumped equivalent of $\left[\log _{10}\left(\Gamma_{k, i}\right)+\Delta g_{k}(T) / 2.303 R T\right]$.

In SIMPOL.1, the $T$ dependence in each of the $b_{k}(T)$ is fit to its own set of $B_{1, k}$ to $B_{4, k}$ according to

$b_{k}(T)=\frac{B_{1, k}}{T}+B_{2, k}+B_{3, k} T+B_{4, k} \ln T$

which is the form of the $T$ dependence utilized for the 17 coefficients in the UNIFAC model of Jensen et al. (1981). The goal of this work is to use $p_{\mathrm{L}, i}^{\mathrm{o}}(T)$ data for a wide range of compounds to obtain best-fit functional representations of the $b_{k}(T)$.

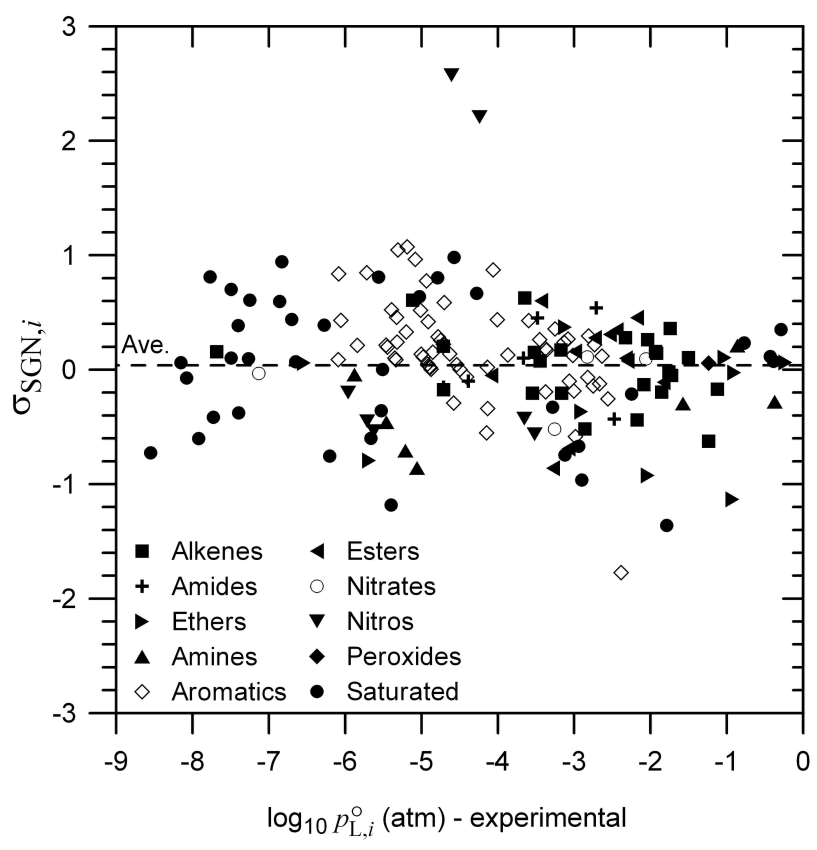

Fig. 6. $\sigma_{\mathrm{SGN}, i}$ at $333.15 \mathrm{~K}$ for the test set compounds calculated as defined in Eq. (14) plotted vs. experimentally derived $\log _{10} p_{\mathrm{L}, i}^{\mathrm{o}}(333.15)$. Predicted $p_{\mathrm{L}, i}^{\mathrm{o}}$ values used in calculating the $\sigma_{\mathrm{SGN}, i}$ are based on the optimization using the initial basis set compounds.

The temperature dependence of $\log _{10} p_{\mathrm{L}, i}^{\mathrm{o}}(T)$ may be used to estimate $\Delta H_{\mathrm{vap}, i}(T)$ according to

$\frac{d \log _{10} p_{\mathrm{L}, i}^{\mathrm{o}}(T)}{d(1 / T)}=-\frac{\Delta H_{\mathrm{vap}, i}(T)}{2.303 R}$

Thus, by Eq. (6)

$\Delta H_{\mathrm{vap}, i}(T)=-2.303 R \sum_{k} v_{k, i} \frac{d b_{k}(T)}{d(1 / T)}$

Eq. (10) may be viewed as a group contribution expression for $\Delta H_{\mathrm{vap}, i}(T)$ based on the SIMPOL.1 framework where the group contribution to $\Delta H_{\mathrm{vap}, i}(T)$, defined as $\Delta h_{\mathrm{vap}, i}(T)$, is given by each term in the summation in Eq. (10). Eq. (10) may also be used to derive the predicted change in $\Delta H_{\mathrm{vap}, i}(T)$ as a function of $T$ in the SIMPOL.1 framework. Substitution of the functional form for $b_{k}$ given in Eq. (8) into Eq. (10) and taking the derivative with respect to $T$ results in

$\frac{d \Delta H_{\mathrm{vap}, i}(T)}{d T}=\sum_{k} v_{k, i}\left[2.303 R\left(2 B_{3, k} T+B_{4, k}\right)\right]$

where the SIMPOL.1 group contribution to $d \Delta H_{\mathrm{vap}, i}(T) / d T$ is defined as $d \Delta h_{\mathrm{vap}, i}(T) / d T$.

For any real compound $i$ in the liquid state, $\Delta H_{\mathrm{vap}, i}(T)>0$, but $d \Delta H_{\mathrm{vap}, i}(T) / d T<0$ because $\Delta H_{\mathrm{vap}, i}$ decreases monotonically to zero as $T$ approaches the compound's critical temperature $T_{c, i}$ (Reid et al., 1986). (As 
Table 3a.

Non-oxygenated, hydroxyl, phenolic, aldehyde, ketone, and carboxylic acid compounds in the test set for the initial fit.

\begin{tabular}{|c|c|c|}
\hline Hydroxyls & Aldehydes and Ketones & Carboxylic Acids (cont.) \\
\hline 2-methyl, 2,4 pentanediol & 2-acetyl-cyclopentanone & pinic acid \\
\hline 1,6 hexanediol & 2-hydroxy-2-methyl-3-hexanone & norpinic acid \\
\hline 2,3 dimethyl 2,3 butanediol & pinonaldehyde & 15-hydroxy-pentadecanoic acid \\
\hline 1,7-heptanediol & caronaldehyde & 16-hydroxy-hexadecanoic acid \\
\hline 1,2,3-trihydroxy-propane & 5-hexenal & 12-hydroxy-octadecanoic acid \\
\hline 4-methyl-4-penten-2-ol & 2-cyclohexen-1-one & 2-oxo-pentanedioic acid \\
\hline 2-methyl-cyclohex-1-enyl-methanol & 5-methyl-5-hexen-2-one & 3-oxo-pentanedioic acid \\
\hline cis-2-butene-1,4-diol & 2-ethyl-hex-2-enal & 2-oxohexanedioic acid \\
\hline oct-2-en-4-ol & 3,4-dimethyl-hex-3-en-2-one & 3-oxohexanedioic acid \\
\hline 3,7-dimethyl-oct-6-en-1-ol & 6-methyl-hept-3-en-2-one & 5-oxo-nonanedioic acid \\
\hline 5-decen-1-ol & 6-methyl-hept-5-en-2-one & 5-hexenoic acid \\
\hline 9-decen-1-ol & 5-methyl-hept-4-en-3-one & 2-octenoic acid \\
\hline 2-phenyl-1-propanol & oct-2-enal & 3,7-dimethyl-oct-6-enoic \\
\hline 3-phenyl-1-butanol & 3-octen-2-one & 2-decenoic acid \\
\hline 1-phenyl-ethanol & 2-allyl-2-methyl-cyclopentane-1,3-dione & 9-undecenoic acid \\
\hline 1-phenyl-1-propanol & 1-phenyl-2-butanone & octadeca-9-enoic acid \\
\hline 1-phenyl-2-propanol & 3-phenyl-1-butanal & benzoic acid \\
\hline 3-phenyl-1-propanol & 1-(3-methyl-phenyl)-ethanone & 2-methyl-benzoic acid \\
\hline 3-phenyl-2-propen-1-ol & 1-(4-methyl-phenyl)-ethanone & 3-phenyl-propanoic acid \\
\hline Phenols & 1-(2,4-dimethylphenyl)-ethanone & 4-phenyl-butanoic acid \\
\hline 3-ethyl-phenol & 1-(2-ethyl-phenyl)-ethanone & 5-phenyl-pentanoic acid \\
\hline p-hydroxybiphenyl & 1-phenyl-1-propanone & 2,3-dimethyl benzoic acid \\
\hline o-hydroxybiphenyl & 1-phenyl-1-butanone & 2,4-dimethyl benzoic acid \\
\hline 4-(phenylmethyl)-phenol & 4-phenyl-2-butanone & 2,5-dimethyl benzoic acid \\
\hline$p$-(1,1-dimethylethyl)-phenol & 2,4-dimethyl-benzaldehyde & 2,6-dimethyl benzoic acid \\
\hline 2-(1,1-dimethylethyl)-4-methylphenol & 4-(1-methylethyl)-benzaldehyde & 3,4-dimethyl benzoic acid \\
\hline 2-methyl-4-(1,1-dimethylethyl)-phenol & 2-hydroxy-benzaldehyde & 3,5-dimethyl benzoic acid \\
\hline 5-methyl-2-(1,1-dimethylethyl)-phenol & 4-hydroxy-benzaldehyde & 2,3,4-trimethyl benzoic acid \\
\hline 2,4,6-tri-(1,1-dimethylethyl)-phenol & Carboxylic Acids & 2,3,5-trimethyl benzoic acid \\
\hline 1-(4-hydroxyphenyl)-ethanone & 2-ethyl-hexanoic acid & 2,3,6-trimethyl benzoic acid \\
\hline 1-napthol & propanedioic acid & 2,4,5-trimethyl benzoic acid \\
\hline 2-napthol & hexanedioic acid & 2,4,6-trimethyl benzoic acid \\
\hline 2-propyl phenol & heptanedioic acid & 3,4,5-trimethyl benzoic acid \\
\hline 4-propyl phenol & octanedioic acid & 2-(1-methylethyl) benzoic acid \\
\hline 2-(1-methyl-ethyl)-phenol & nonanedioic acid & 3-(1-methylethyl) benzoic acid \\
\hline 3-(1-methyl-ethyl)-phenol & decanedioic acid & 4-(1-methylethyl) benzoic acid \\
\hline Saturated Non-oxygenated & undecanedioic acid & 2,3,4,5-tetramethyl benzoic acid \\
\hline cyclohexane & dodecanedioic acid & 2,3,4,6-tetramethyl benzoic acid \\
\hline 1,1-dimethyl cyclopentane & 3-methyl-hexanedioic acid & 2,3,5,6-tetramethyl benzoic acid \\
\hline trans-1,3-dimethyl cyclopentane & 2,2-dimethyl-butanedioic acid & 2-(1,1-dimethylethyl) benzoic acid \\
\hline 2,3,4-trimethyl pentane & 2-methyl-butanedioic acid & 3-(1,1-dimethylethyl) benzoic acid \\
\hline \multirow[t]{2}{*}{ 2,2,3,3-tetramethyl butane } & 2-methyl-pentanedioic acid & 4-(1,1-dimethylethyl) benzoic acid \\
\hline & 2,2-dimethyl-pentanedioic acid & pentamethyl benzoic acid \\
\hline
\end{tabular}

$T \rightarrow T_{c, i}$, the liquid and gas states for $i$ become increasingly similar, and less and less thermal energy is required for the phase transition.) It is desirable, then, that the values of the fitted parameters used in Eq. (10) yield $d \Delta H_{\mathrm{vap}, i}(T) / d T<0$ with Eq. (11). The extent to which this is observed depends upon the reliability of the $p_{\mathrm{L}, i}^{\mathrm{o}}(T)$ data set used in the fitting (including adequate coverage by the data of suitably wide temperature ranges for a mix of compounds that contains all the groups of interest) and the ability of the chosen groups to represent the physical properties of $i$.

\subsection{Fitting the SIMPOL. 1 coefficients}

All $B_{1, k}-B_{4, k}$ sets were determined by an optimization process using a set of compounds with measured $p_{\mathrm{L}}^{\mathrm{o}}(T)$ values. See Asher et al. (2002) and Asher and Pankow (2006) for descriptions of this type of process. The optimization used nonlinear regression to minimize a least-squares goodnessof-fit criterion defined as 
Table 3b. Amide, amine, ester, ether, nitrate, nitro-containing, and peroxide compounds in the test set for the initial fit.

\begin{tabular}{|c|c|}
\hline Amides & Ethers \\
\hline heptanamide & 4-methyl-1,3-dioxane \\
\hline octanamide & 1,3-dioxepan \\
\hline methyl-butyramide & 1,3-dioxolan \\
\hline diethyl-butanamide & dimethoxy methane \\
\hline dimethyl-cyclohexanecarboxamide & trans-2,2,4,6-tetramethyl-1,3-dioxane \\
\hline 1-methyl-piperidin-2-one & $\begin{array}{l}\text { 2-(2-methoxyethoxy)-tetrahydropyran } \\
\text { (phenoxymethyl)-oxirane }\end{array}$ \\
\hline Amines & 2-phenyl-1,3-dioxolane \\
\hline 1-amino-2,6-dimethylbenzene & 2,3-dimethoxybenzoic acid \\
\hline$n$-ethyl- $n$-phenylamine & 2,4-dimethoxybenzoic acid \\
\hline \multicolumn{2}{|l|}{ 1-amino-2,4-dimethylbenzene } \\
\hline 1-amino-4-ethylbenzene & Nitrates \\
\hline triethanolamine & cyclohexane nitrate \\
\hline dibutylamine & phenylmethyl nitrate \\
\hline hexylamine & 2,2'-oxybis-ethanol dinitrate \\
\hline \multicolumn{2}{|l|}{$n$-(1-methylethyl)-2-propanamine } \\
\hline 1-(diethylamino)-2-propanone & Nitros \\
\hline 2-amino-3-methylbenzoic & 2,4-dinitrophenol \\
\hline 2-amino-5-methylbenzoic & 2,5-dinitrophenol \\
\hline 2-amino-6-methylbenzoic & 3-nitrophenol \\
\hline \multirow[t]{2}{*}{ 3-amino-2-methylbenzoic } & 4-nitrophenol \\
\hline & 2-methyl-6-nitrobenzoic acid \\
\hline Esters & 3-methyl-2-nitrobenzoic acid \\
\hline $\begin{array}{l}\text { dimethyl 1,4-benzenedicarboxylate } \\
\text { methyl dimethoxyethanoate }\end{array}$ & 3-methyl-4-nitrobenzoic acid \\
\hline diethyl 1,1-cyclopentanedicarboxylate & Peroxides \\
\hline dimethyl propanedioate & di-(1-methyl-propyl) peroxide \\
\hline \multicolumn{2}{|l|}{ 1,2-ethanediol diacetate } \\
\hline \multicolumn{2}{|l|}{ methyl benzoate } \\
\hline \multicolumn{2}{|l|}{ phenyl acetate } \\
\hline \multicolumn{2}{|l|}{ ethyl benzoate } \\
\hline \multicolumn{2}{|l|}{ diethyl 1,1-cyclobutanedicarboxylate } \\
\hline \multicolumn{2}{|l|}{ n-propyl benzoate } \\
\hline \multicolumn{2}{|l|}{ 2-methyl-propyl benzoate } \\
\hline n-butyl benzoate & \\
\hline
\end{tabular}

$\chi^{2}=\sum_{i=1}^{N_{\mathrm{c}}} \sum_{j=1}^{N_{\mathrm{T}, i}}\left(\log _{10}\left(p_{\mathrm{L}, i}^{\mathrm{o}}\left(T_{j, i}\right)\right)_{\mathrm{E}}\right.$

$\left.-\left[b_{0}\left(T_{j, i}\right)+\sum_{k=1}^{N_{\mathrm{G}}} v_{k, i} b_{k}\left(T_{j, i}\right)\right]\right)^{2}$

where: $N_{\mathrm{c}}$ is the number of compounds (=272 for the initial basis set); $N_{\mathrm{G}}$ is the total number of groups considered; and each $\left(p_{\mathrm{L}, i}^{\mathrm{o}}\left(T_{j, i}\right)\right)_{\mathrm{E}}$ is the vapor pressure of $i$ at temperature $T$ as evaluated using a $p_{\mathrm{L}, i}^{\mathrm{o}}=f_{i}(T)$ expression (e.g., an Antoine-type equation) fitted to experimentally derived $p_{\mathrm{L}, i}^{\mathrm{o}}$ data. The $f_{i}(T)$ expressions used and the associated references are provided in the supplementary online materials http://www.atmos-chem-phys.net/ 8/2773/2008/acp-8-2773-2008-supplement.pdf. The optimizations were performed using $T_{j, i}$ that could take on the discrete values of $273.15,293.15, \ldots 393.15 \mathrm{~K}$ with all $p_{\mathrm{L}, i}^{\mathrm{o}}$ calculated in units of atmospheres. For compounds for which $f_{i}(T)$ had been fit over that entire range, $N_{\mathrm{T}, i}=7$; for others, $N_{\mathrm{T}, i}<7$. With the initial basis set compounds, the total number of points considered in the optimization was $N=1844$.

\subsection{Groups and initial basis set compounds}

In addition to the zeroeth group, 30 structural groups are considered, giving the total number of groups $N_{\mathrm{G}}=31$. In addition to molecular carbon (for which $k=1$ ), the first-order groups considered are: alkyl hydroxyl, aromatic hydroxyl (e.g., phenol), alkyl ether, alkyl ring ether (e.g, dioxane), aro- 
Table 4. Average standard errors in vapor pressures for the test set compounds as estimated by SIMPOL.1 based on the initial basis set compounds in Table 1 and all $T_{j, i}$ for which the experimentally based $p_{\mathrm{L}, i}^{\mathrm{o}}=f_{i}(T)$ expressions extended.

\begin{tabular}{lccr}
\hline Compounds & $\begin{array}{c}\text { number of compounds } \\
N_{\mathrm{c}}\end{array}$ & $\begin{array}{c}\text { average absolute error } \\
\sigma_{\text {FIT }} \log (\mathrm{atm})\end{array}$ & $\begin{array}{r}\text { average signed error } \\
\sigma_{\text {SGN }} \log (\mathrm{atm})\end{array}$ \\
\hline All compounds & 184 & 0.45 & $7.1 \times 10^{-2}$ \\
Alkenes & 24 & 0.29 & $2.8 \times 10^{-2}$ \\
Amides & 6 & 0.41 & $7.1 \times 10^{-2}$ \\
Amines & 14 & 0.39 & $-1.3 \times 10^{-1}$ \\
Aromatics & 68 & 0.39 & $2.0 \times 10^{-1}$ \\
Carbonylperoxynitrates & 0 & n.a. ${ }^{\mathrm{a}}$ & n.a. \\
Esters & 12 & 0.36 & $5.7 \times 10^{-2}$ \\
Ethers & 10 & 0.42 & $-2.5 \times 10^{-1}$ \\
Hydroperoxides & 0 & n.a. ${ }^{\mathrm{a}}$ & n.a. \\
Nitrates & 4 & 0.29 & $-1.1 \times 10^{-1}$ \\
Nitro-containing & 7 & 1.0 & $3.8 \times 10^{-1}$ \\
Peroxides & 1 & 0.23 & $2.4 \times 10^{-2}$ \\
Peroxyacids & 0 & n.a. ${ }^{\mathrm{a}}$ & n.a..$^{\mathrm{a}}$ \\
Saturated & 38 & 0.66 & $2.5 \times 10^{-3}$ \\
& & & \\
\hline
\end{tabular}

a n.a.=not available
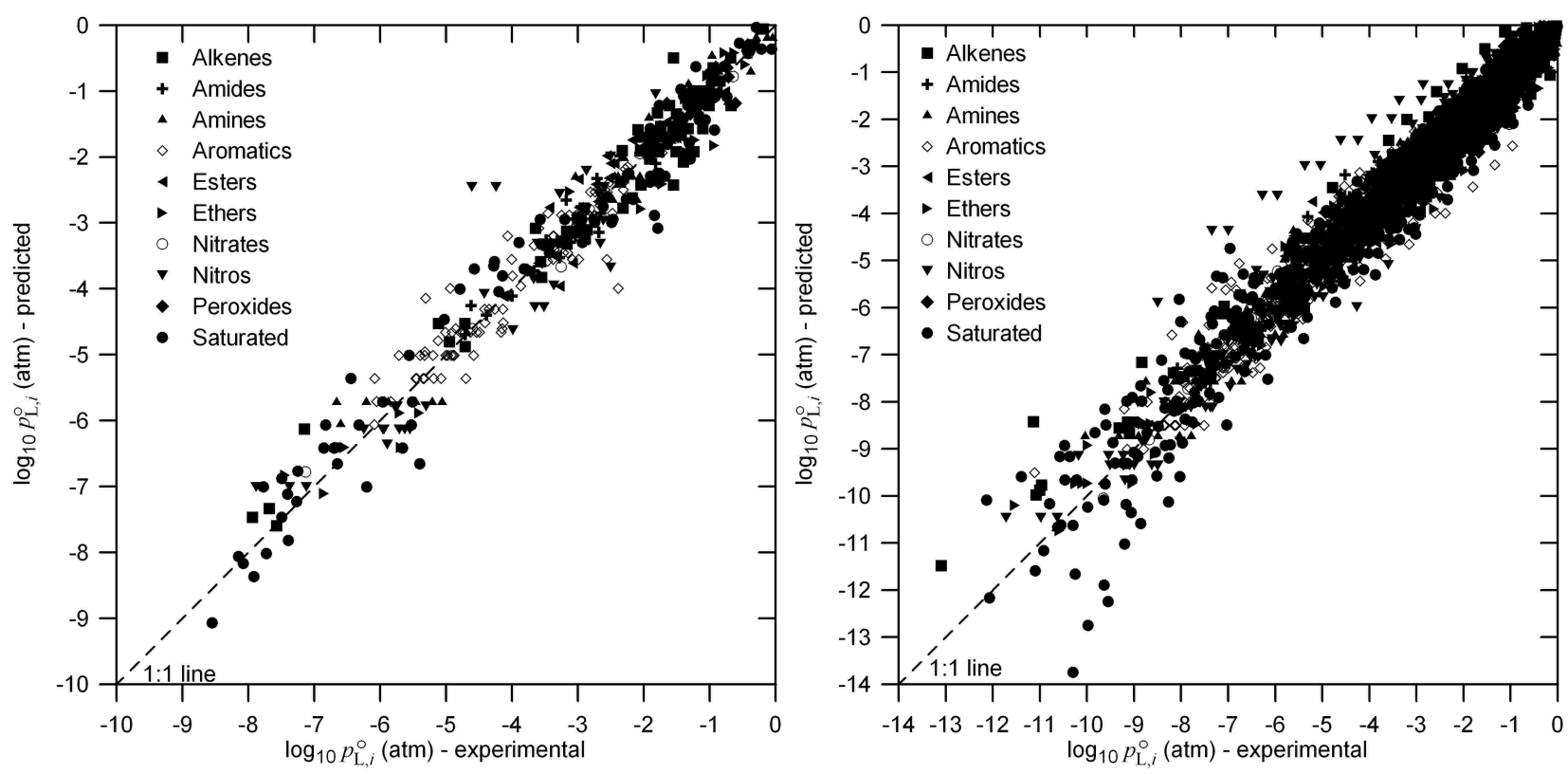

Fig. 7. (a) Predicted vs. experimentally derived $p_{\mathrm{L}, i}^{\mathrm{o}}$ at $T=333.15 \mathrm{~K}$ for all compounds based on the final optimization using all of the compounds.

(b) Predicted vs. experimentally derived $p_{\mathrm{L}, i}^{\mathrm{o}}$ at all seven temperatures for all compounds based on the final optimization using all of the compounds to show the complete data range.

matic ether (e.g., methoxybenzene), aldehyde, ketone, carboxylic acid, ester, nitrate, nitro, alkyl amine (primary, secondary, and tertiary), aromatic amine (e.g., aniline), amide (primary, secondary, and tertiary), peroxide, hydroperoxide, peroxy acid, $\mathrm{C}=\mathrm{C}$, and carbonylperoxynitrate. The second- order groups considered are: carbon on the acid-side of an amide for which $k=2$ (e.g., for $n$-propyl-butyramide, $v_{1}=7$ and $v_{2}=4$ ); nitro-phenol (as in 2-nitro-phenol), nitro-ester (as in methyl nitroacetate), aromatic rings, non-aromatic rings (as in cyclohexane), and $\mathrm{C}=\mathrm{C}-\mathrm{C}=\mathrm{O}$ in a non-aromatic 
Table 5. Chemical groups used in SIMPOL.1 and the $B$ values obtained by least-squares optimization using the final fitting set (all compounds in Tables 1 and 3) and giving $\chi^{2}=728$. Coefficient set predicts $p_{\mathrm{L}, i}^{\mathrm{o}}$ in atmospheres.

\begin{tabular}{|c|c|c|c|c|c|c|c|}
\hline groups & $k$ & coefficient & footnote comment & $B_{k, 1}$ & $B_{k, 2}$ & $B_{k, 3}$ & $B_{k, 4}$ \\
\hline $\begin{array}{l}\text { zeroeth group } \\
\text { (constant term) }\end{array}$ & 0 & $b_{0}$ & $\mathrm{a}$ & $-4.26938 \mathrm{E}+02$ & 2.89223E-01 & 4.42057E-03 & $2.92846 \mathrm{E}-01$ \\
\hline carbon number & 1 & $b_{1}$ & $\mathrm{~b}$ & $-4.11248 \mathrm{E}+02$ & 8.96919E-01 & $-2.48607 \mathrm{E}-03$ & 1.40312E-01 \\
\hline $\begin{array}{l}\text { carbon number on the } \\
\text { acid-side of an amide (asa) }\end{array}$ & 2 & $b_{2}$ & c & $-1.46442 \mathrm{E}+02$ & $1.54528 \mathrm{E}+00$ & $1.71021 \mathrm{E}-03$ & $-2.78291 \mathrm{E}-01$ \\
\hline aromatic ring & 3 & $b_{3}$ & d & $3.50262 \mathrm{E}+01$ & $-9.20839 \mathrm{E}-01$ & 2.24399E-03 & $-9.36300 \mathrm{E}-02$ \\
\hline non-aromatic ring & 4 & $b_{4}$ & e & $-8.72770 \mathrm{E}+01$ & $1.78059 \mathrm{E}+00$ & $-3.07187 \mathrm{E}-03$ & $-1.04341 \mathrm{E}-01$ \\
\hline $\mathrm{C}=\mathrm{C}$ (non-aromatic) & 5 & $b_{5}$ & $\mathrm{f}$ & $5.73335 \mathrm{E}+00$ & 1.69764E-02 & $-6.28957 \mathrm{E}-04$ & 7.55434E-03 \\
\hline $\begin{array}{l}\mathrm{C}=\mathrm{C}-\mathrm{C}=\mathrm{O} \text { in } \\
\text { non-aromatic ring }\end{array}$ & 6 & $b_{6}$ & g & $-2.61268 \mathrm{E}+02$ & $-7.63282 \mathrm{E}-01$ & $-1.68213 \mathrm{E}-03$ & 2.89038E-01 \\
\hline hydroxyl (alkyl) & 7 & $b_{7}$ & $\mathrm{~h}$ & $-7.25373 \mathrm{E}+02$ & $8.26326 \mathrm{E}-01$ & $2.50957 \mathrm{E}-03$ & $-2.32304 \mathrm{E}-01$ \\
\hline aldehyde & 8 & $b_{8}$ & $\mathrm{i}$ & $-7.29501 \mathrm{E}+02$ & 9.86017E-01 & $-2.92664 \mathrm{E}-03$ & 1.78077E-01 \\
\hline ketone & 9 & $b_{9}$ & $\mathrm{j}$ & $-1.37456 \mathrm{E}+01$ & $5.23486 \mathrm{E}-01$ & $5.50298 \mathrm{E}-04$ & $-2.76950 \mathrm{E}-01$ \\
\hline carboxylic acid & 10 & $b_{10}$ & $\mathrm{k}$ & $-7.98796 \mathrm{E}+02$ & $-1.09436 \mathrm{E}+00$ & 5.24132E-03 & $-2.28040 \mathrm{E}-01$ \\
\hline ester & 11 & $b_{11}$ & $L$ & $-3.93345 \mathrm{E}+02$ & $-9.51778 \mathrm{E}-01$ & $-2.19071 \mathrm{E}-03$ & 3.05843E-01 \\
\hline ether & 12 & $b_{12}$ & $\mathrm{~m}$ & $-1.44334 \mathrm{E}+02$ & $-1.85617 \mathrm{E}+00$ & $-2.37491 \mathrm{E}-05$ & $2.88290 \mathrm{E}-01$ \\
\hline ether (alicyclic) & 13 & $b_{13}$ & $\mathrm{~m}$ & $4.05265 \mathrm{E}+01$ & $-2.43780 \mathrm{E}+00$ & 3.60133E-03 & $9.86422 \mathrm{E}-02$ \\
\hline ether, aromatic & 14 & $b_{14}$ & $\mathrm{~m}$ & $-7.07406 \mathrm{E}+01$ & $-1.06674 \mathrm{E}+00$ & 3.73104E-03 & $-1.44003 \mathrm{E}-01$ \\
\hline nitrate & 15 & $b_{15}$ & $\mathrm{n}$ & $-7.83648 \mathrm{E}+02$ & $-1.03439 \mathrm{E}+00$ & $-1.07148 \mathrm{E}-03$ & 3.15535E-01 \\
\hline nitro & 16 & $b_{16}$ & o & $-5.63872 \mathrm{E}+02$ & $-7.18416 \mathrm{E}-01$ & 2.63016E-03 & $-4.99470 \mathrm{E}-02$ \\
\hline $\begin{array}{l}\text { aromatic hydroxyl } \\
\text { (e.g., phenol) }\end{array}$ & 17 & $b_{17}$ & $\mathrm{p}$ & $-4.53961 \mathrm{E}+02$ & $-3.26105 \mathrm{E}-01$ & $-1.39780 \mathrm{E}-04$ & $-3.93916 \mathrm{E}-02$ \\
\hline amine, primary & 18 & $b_{18}$ & $\mathrm{q}$ & $3.71375 \mathrm{E}+01$ & $-2.66753 \mathrm{E}+00$ & $1.01483 \mathrm{E}-03$ & 2.14233E-01 \\
\hline amine, secondary & 19 & $b_{19}$ & $\mathrm{q}$ & $-5.03710 \mathrm{E}+02$ & $1.04092 \mathrm{E}+00$ & $-4.12746 \mathrm{E}-03$ & $1.82790 \mathrm{E}-01$ \\
\hline amine, tertiary & 20 & $b_{20}$ & $\mathrm{q}$ & $-3.59763 \mathrm{E}+01$ & $-4.08458 \mathrm{E}-01$ & $1.67264 \mathrm{E}-03$ & $-9.98919 \mathrm{E}-02$ \\
\hline amine, aromatic & 21 & $b_{21}$ & $\mathrm{q}$ & $-6.09432 \mathrm{E}+02$ & $1.50436 \mathrm{E}+00$ & $-9.09024 \mathrm{E}-04$ & $-1.35495 \mathrm{E}-01$ \\
\hline amide, primary & 22 & $b_{22}$ & c & $-1.02367 \mathrm{E}+02$ & $-7.16253 \mathrm{E}-01$ & $-2.90670 \mathrm{E}-04$ & $-5.88556 \mathrm{E}-01$ \\
\hline amide, secondary & 23 & $b_{23}$ & $\mathrm{c}$ & $-1.93802 \mathrm{E}+03$ & $6.48262 \mathrm{E}-01$ & $1.73245 \mathrm{E}-03$ & $3.47940 \mathrm{E}-02$ \\
\hline amide, tertiary & 24 & $b_{24}$ & $\mathrm{c}$ & $-5.26919 \mathrm{E}+00$ & $3.06435 \mathrm{E}-01$ & $3.25397 \mathrm{E}-03$ & $-6.81506 \mathrm{E}-01$ \\
\hline carbonylperoxynitrate & 25 & $b_{25}$ & $\mathrm{r}$ & $-2.84042 \mathrm{E}+02$ & $-6.25424 \mathrm{E}-01$ & $-8.22474 \mathrm{E}-04$ & $-8.80549 \mathrm{E}-02$ \\
\hline peroxide & 26 & $b_{26}$ & $\mathrm{r}$ & $1.50093 \mathrm{E}+02$ & $2.39875 \mathrm{E}-02$ & $-3.37969 \mathrm{E}-03$ & $1.52789 \mathrm{E}-02$ \\
\hline hydroperoxide & 27 & $b_{27}$ & $\mathrm{r}$ & $-2.03387 \mathrm{E}+01$ & $-5.48718 \mathrm{E}+00$ & 8.39075E-03 & $1.07884 \mathrm{E}-01$ \\
\hline carbonylperoxyacid & 28 & $b_{28}$ & $\mathrm{r}$ & $-8.38064 \mathrm{E}+02$ & $-1.09600 \mathrm{E}+00$ & $-4.24385 \mathrm{E}-04$ & 2.81812E-01 \\
\hline nitrophenol & 29 & $b_{29}$ & $\mathrm{p}$ & $-5.27934 \mathrm{E}+01$ & $-4.63689 \mathrm{E}-01$ & $-5.11647 \mathrm{E}-03$ & $3.84965 \mathrm{E}-01$ \\
\hline nitroester & 30 & $b_{30}$ & $L$ & $-1.61520 \mathrm{E}+03$ & $9.01669 \mathrm{E}-01$ & $1.44536 \mathrm{E}-03$ & $2.66889 \mathrm{E}-01$ \\
\hline
\end{tabular}

${ }^{\text {a }}$ Use for all compounds $i$ with $v_{0, i}=1$.

${ }^{\mathrm{b}}$ Use for all compounds $i$ with $v_{1, i}=$ total number of carbons in the molecule.

c If the compound is an amide, use both $b_{1}$ and $b_{2}$. Examples: for acetamide, use $b_{0}, b_{1}, b_{2}$, and $b_{22}$, for methyl acetamide, use $b_{0}, b_{1}, b_{2}$, and $b_{23}$, for methyl ethyl acetamide, use $b_{0}, b_{1}, b_{2}$, and $b_{24}$.

${ }^{\mathrm{d}}$ Use with total number of aromatic rings in a molecule. Examples: for biphenyl, use $b_{0}, b_{1}$, and $b_{3}$ with $b_{3}=2$; for anthracene, use $b_{0}, b_{1}$, and $b_{3}$ with $b_{3}=3$.

e Use with total number of non-aromatic rings in a molecule. Examples: for cyclohexane, use $b_{0}, b_{1}$, and $b_{4}$ with $b_{4}=1$.

${ }^{\mathrm{f}}$ Use with total number of non-aromatic $\mathrm{C}=\mathrm{C}$ bonds. Example: for 1-hexene, use $b_{0}, b_{1}$, and $b_{5}$ with $b_{5}=1$.

$\mathrm{g}$ Use with total number of $\mathrm{C}=\mathrm{C}-\mathrm{C}=\mathrm{O}$ groups in non-aromatic rings. Example: for cyclohex-2-eneone, use $b_{0}, b_{1}, b_{4}, b_{5}, b_{6}$, and $b_{9}$ with $b_{4}, b_{5}, b_{6}$, and $b_{9}$ all equal to 1 .

${ }^{\mathrm{h}}$ Use with total number of hydroxyl groups attached to non-aromatic carbons.

${ }^{\mathrm{i}}$ Use with total number of aldehyde groups.

$\mathrm{j}$ Use with total number of ketone groups.

${ }^{\mathrm{k}}$ Use with total number of carboxylic acid groups.

${ }^{L}$ Use with total number of ester groups unless there is a nitro bonded to the acid side carbon chain of the ester, in this case use $b_{30}$. Examples: for methyl acetate, use $b_{0}, b_{1}$, and $b_{11}$; for methyl nitroacetate, use $b_{0}, b_{1}, b_{16}$, and $b_{30}$.

${ }^{\mathrm{m}}$ Use with ether groups. If both carbons bonded to the oxygen are not part of an aromatic ring, use $b_{12}$. If the oxygen is within a non-aromatic ring use $b_{13}$. Otherwise, use $b_{14}$. Examples for dimethylether, use $b_{0}, b_{1}$, and $b_{12}$; for tetrahydrofuran, use $b_{0}, b_{1}, b_{4}$, and $b_{13}$; for methylphenyl ether, use $b_{0}, b_{1}, b_{3}$, and $b_{14}$.

${ }^{\mathrm{n}}$ Use with total number of nitrate groups.

${ }^{\circ}$ Use with total number of nitro groups. Examples: use $b_{0}, b_{1}$, and $b_{16}$ for 2-nitropropane; use $b_{0}, b_{1}, b_{3}$, and $b_{16}$ for nitrobenzene.

p Use with total number of aromatic hydroxyls (i.e., phenolic hydroxyls) unless there is a nitro group bonded to a benzene ring, in which case use $b_{29}$. Examples: for 2-methylphenol, use $b_{0}, b_{1}, b_{3}$, and $b_{17}$; for 2-nitrophenol, use $b_{0}, b_{1}, b_{3}, b_{16}$, and $b_{29}$.

q Use with amines. If all carbons bonded to the nitrogen are not aromatic, use $b_{11}$ or $b_{12}$ or $b_{13}$. Otherwise, use $b_{14}$. Examples: for methylamine use $b_{0}, b_{1}$, and $b_{11}$; for dimethylamine use $b_{0}, b_{1}$, and $b_{12}$; for trimethylamine and for N-benzyl-dimethylamine use $b_{0}, b_{1}$, and $b_{13}$; for phenylamine, for N-methyl-N-phenylamine, and for N,N-dimethylN-phenylamine, use $b_{0}, b_{1}$, and $b_{14}$.

${ }^{\mathrm{r}}$ Use with peroxy compounds. Examples: for peroxy propanyl nitrate use $b_{0}, b_{1}$, and $b_{25}$; for N-propyl-N-butyl peroxide use $b_{0}, b_{1}$, and $b_{26}$; for N-butyl peroxide use $b_{0}, b_{1}$, and $b_{27}$; and for peroxyacetic acid use $b_{0}, b_{1}$, and $b_{28}$. 
Table 6. Values at $T=293.15 \mathrm{~K}$ of the $b_{k}$ group contribution terms from this work, the $\tau$ group contribution terms from Capouet and Müller (2006), and for each method whether each group value $d \Delta h_{\mathrm{vap}} / d T<0$ at $T=293.15 \mathrm{~K}$.

\begin{tabular}{|c|c|c|c|c|c|c|}
\hline \multirow[b]{2}{*}{ groups } & \multirow[b]{2}{*}{$k$} & \multirow[b]{2}{*}{ coefficient } & \multirow{2}{*}{$\begin{array}{c}\text { this work } \\
\text { value of } b_{k} \\
T=293.15\end{array}$} & \multirow[b]{2}{*}{$\begin{array}{c}\frac{d \Delta h_{\mathrm{vap}, k}(T)}{d T}<0 ? \\
T=293.15 \mathrm{~K}\end{array}$} & \multicolumn{2}{|c|}{ Capouet and Müller (2006) } \\
\hline & & & & & $\begin{array}{l}\text { value of } \tau_{k} \\
T=293.15\end{array}$ & $\begin{array}{c}\frac{d \Delta h_{\mathrm{vap}}(T)}{d T}<0 ? \\
T=293.15 \mathrm{~K}\end{array}$ \\
\hline zeroeth group (constant term) & 0 & $b_{0}$ & 1.79 & NO & $-{ }^{\mathrm{a}}$ & - \\
\hline carbon number & 1 & $b_{1}$ & -0.438 & YES & - & - \\
\hline carbon number, acid-side of amide & 2 & $b_{2}$ & -0.0338 & NO & - & - \\
\hline number of aromatic rings & 3 & $b_{3}$ & -0.675 & NO & - & - \\
\hline number of non-aromatic rings & 4 & $b_{4}$ & -0.0104 & YES & - & - \\
\hline $\mathrm{C}=\mathrm{C}($ non-aromatic $)$ & 5 & $b_{5}$ & -0.105 & YES & - & - \\
\hline $\mathrm{C}=\mathrm{C}-\mathrm{C}=\mathrm{O}$ in non-aromatic ring & 6 & $b_{6}$ & -0.506 & YES & - & - \\
\hline hydroxyl (alkyl) & 7 & $b_{7}$ & -2.23 & NO & $-2.76,-2.10,-1.49^{b}$ & no \\
\hline aldehyde & 8 & $b_{8}$ & -1.35 & YES & & \\
\hline ketone & 9 & $b_{9}$ & -0.935 & NO & $-0.91^{\circ}$ & no \\
\hline carboxylic acid & 10 & $b_{10}$ & -3.58 & NO & -3.10 & no \\
\hline ester & 11 & $b_{11}$ & -1.20 & YES & - & - \\
\hline ether & 12 & $b_{12}$ & -0.718 & NO & - & - \\
\hline ether (alicyclic) & 13 & $b_{13}$ & -0.683 & NO & - & - \\
\hline ether, aromatic & 14 & $b_{14}$ & -1.03 & NO & - & - \\
\hline nitrate & 15 & $b_{15}$ & -2.23 & YES & $-2.12,-1.70,-1.30^{\mathrm{d}}$ & no \\
\hline nitro & 16 & $b_{16}$ & -2.15 & NO & - & - \\
\hline aromatic hydroxyl (e.g., phenol) & 17 & $b_{17}$ & -2.14 & YES & - & - \\
\hline amine, primary & 18 & $b_{18}$ & -1.03 & NO & - & - \\
\hline amine, secondary & 19 & $b_{19}$ & -0.849 & YES & - & - \\
\hline amine, tertiary & 20 & $b_{20}$ & -0.608 & NO & - & - \\
\hline amine, aromatic & 21 & $b_{21}$ & -1.61 & YES & - & - \\
\hline amide, primary & 22 & $b_{22}$ & -4.49 & YES & - & - \\
\hline amide, secondary & 23 & $b_{23}$ & -5.26 & NO & - & - \\
\hline amide, tertiary & 24 & $b_{24}$ & -2.63 & NO & - & - \\
\hline carbonylperoxynitrate & 25 & $b_{25}$ & -2.34 & YES & - & - \\
\hline peroxide & 26 & $b_{26}$ & -0.368 & YES & - & - \\
\hline hydroperoxide & 27 & $b_{27}$ & -2.48 & NO & -3.17 & no \\
\hline carbonylperoxyacid & 28 & $b_{28}$ & -2.48 & NO & -3.10 & no \\
\hline nitrophenol & 29 & $b_{29}$ & 0.0432 & YES & - & - \\
\hline nitroester & 30 & $b_{30}$ & -2.67 & NO & - & - \\
\hline
\end{tabular}

a Not considered by Capouet and Müller (2006).

b Primary, secondary, and tertiary hydroxyl, respectively.

c Capouet and Müller (2006) consider only the carbonyl group.

d Primary, secondary, and tertiary nitrate group, respectively.

ring (as in cyclohex-2-enone). Group consideration was not extended to ortho, meta, or para positioning on aromatic rings, or to cis/trans positioning for alkenes.

Table 1 lists the 272 basis set compounds used in the initial fit. There were 6 compounds in the set with primary amide functionality, 4 secondary amides, 4 tertiary amides, 12 primary amines, 4 secondary amines, 3 tertiary amines, 9 aromatic amines, 37 esters, 21 ethers, 10 nitrates, 35 nitros, 3 peroxides, 4 hydroperoxides, 3 peroxy acids, 1 carbonylperoxynitrate, 65 hydroxyls, 6 phenols, 14 aldehydes, 27 ketones, 55 carboxylic acids, 16 aromatic ethers, 16 alkyl ring ethers, 8 nitrophenols, and 5 nitroesters. (These numbers sum to more than 272 because many of the compounds in the basis set had more than one functional group.)

\subsection{Optimization}

There is no general theoretical method for determining whether a local minimum $\chi^{2}$ value found by optimizing the set of $B$ values for Eq. (1) is the desired global minimum. However, beginning the optimization with a large number of suitably different sets of initial $B$ values provides an equal number of optimized $\chi^{2}$ values, and selecting the lowest of these local minima provides a measure of confidence that the corresponding optimized $B$ set either is the set for the global minimum, or is nearly as good as the set for the global minimum.

The $\chi^{2}$ fitting function in Eq. (1) was minimized using the generalized reduced-gradient method (Lasdon et al., 1978) contained in the nonlinear optimization routines LOADNLP and OPTIMIZE from SOLVER.DLL (Frontline Systems, Boulder, Colorado). The optimization was performed in two steps. First, 100 sets of initial $B$ values (with each 
Table 7. Average standard errors in predicting experimental vapor pressures using SIMPOL.1 coefficients optimized for all compounds in Tables 1 and 3 and all $T_{j, i}$ for which the experimentally based $p_{\mathrm{L}, i}^{\mathrm{o}}=f_{i}(T)$ expressions extended. Units of $\sigma_{\mathrm{FIT}}$ and $\sigma_{\mathrm{SGN}}$ are $\log _{10}($ atm).

\begin{tabular}{|c|c|c|c|}
\hline Compounds & $\begin{array}{l}\text { number of compounds } \\
\qquad N_{\mathrm{c}}\end{array}$ & $\begin{array}{l}\text { average absolute error } \\
\qquad \sigma_{\text {FIT }}\end{array}$ & $\begin{array}{c}\text { average signed error } \\
\sigma_{\mathrm{SGN}}\end{array}$ \\
\hline All Compounds & 456 & 0.34 & $-2.3 \mathrm{E}-04$ \\
\hline Alkenes & 64 & 0.32 & $-8.2 \mathrm{E}-03$ \\
\hline Nonoxygenated & 1 & 0.16 & 8.9E-02 \\
\hline Hydroxys & 17 & 0.37 & $-1.7 \mathrm{E}-01$ \\
\hline Cyclic hydroxys & 4 & 0.23 & $1.2 \mathrm{E}-02$ \\
\hline Dihydroxys & 1 & 0.57 & 5.7E-01 \\
\hline Aldehydes & 7 & 0.35 & 2.3E-01 \\
\hline Ketones & 13 & 0.16 & $1.4 \mathrm{E}-01$ \\
\hline Cyclic ketones & 3 & 0.25 & $-8.4 \mathrm{E}-02$ \\
\hline Cyclic hydroxyl ketones & 1 & 0.22 & $-1.4 \mathrm{E}-01$ \\
\hline Carboxylic acids & 15 & 0.41 & $-7.9 \mathrm{E}-02$ \\
\hline Cyclic carboxylics & 2 & 0.25 & $-2.2 \mathrm{E}-01$ \\
\hline Amides & 20 & 0.28 & $1.1 \mathrm{E}-02$ \\
\hline Primary & 8 & 0.28 & $1.6 \mathrm{E}-02$ \\
\hline Secondary & 5 & 0.22 & $2.6 \mathrm{E}-03$ \\
\hline Tertiary & 6 & 0.31 & $-5.4 \mathrm{E}-02$ \\
\hline Cyclic & 1 & 0.40 & 4.0E-01 \\
\hline Amines & 41 & 0.28 & $-9.6 \mathrm{E}-03$ \\
\hline Primary & 11 & 0.22 & $-2.0 \mathrm{E}-03$ \\
\hline Secondary & 8 & 0.25 & $-7.2 \mathrm{E}-02$ \\
\hline Tertiary & 2 & 0.18 & $-1.2 \mathrm{E}-01$ \\
\hline Benzoic acids & 6 & 0.50 & $2.6 \mathrm{E}-02$ \\
\hline Aromatics & 11 & 0.24 & $8.5 \mathrm{E}-03$ \\
\hline Ketones & 2 & 0.23 & $-8.2 \mathrm{E}-02$ \\
\hline Trihydroxys & 1 & 0.52 & 5.2E-01 \\
\hline Aromatics & 89 & 0.32 & $3.6 \mathrm{E}-02$ \\
\hline Nonoxygenated & 3 & 0.26 & $-1.3 \mathrm{E}-01$ \\
\hline Hydroxys & 8 & 0.34 & $1.2 \mathrm{E}-02$ \\
\hline Hydroxy alkenes & 1 & 0.10 & $-1.0 \mathrm{E}-01$ \\
\hline Phenols & 20 & 0.36 & $-4.8 \mathrm{E}-02$ \\
\hline Aldehydes & 6 & 0.28 & 7.9E-02 \\
\hline Ketones & 11 & 0.18 & $1.0 \mathrm{E}-01$ \\
\hline Carbonyl phenols & 3 & 1.17 & 2.3E-01 \\
\hline Benzoic acids & 31 & 0.29 & 8.3E-02 \\
\hline Other carboxylic acids & 5 & 0.16 & $-1.4 \mathrm{E}-01$ \\
\hline Carboxylic acid alkenes & 1 & 0.33 & 3.3E-01 \\
\hline Esters & 42 & 0.25 & $3.0 \mathrm{E}-02$ \\
\hline Monoesters & 23 & 0.23 & 2.3E-02 \\
\hline Diesters & 11 & 0.27 & $-4.4 \mathrm{E}-02$ \\
\hline Cyclic esters & 6 & 0.24 & $6.4 \mathrm{E}-02$ \\
\hline Ether esters & 2 & 0.48 & 4.1E-01 \\
\hline
\end{tabular}


Table 7. Continued.

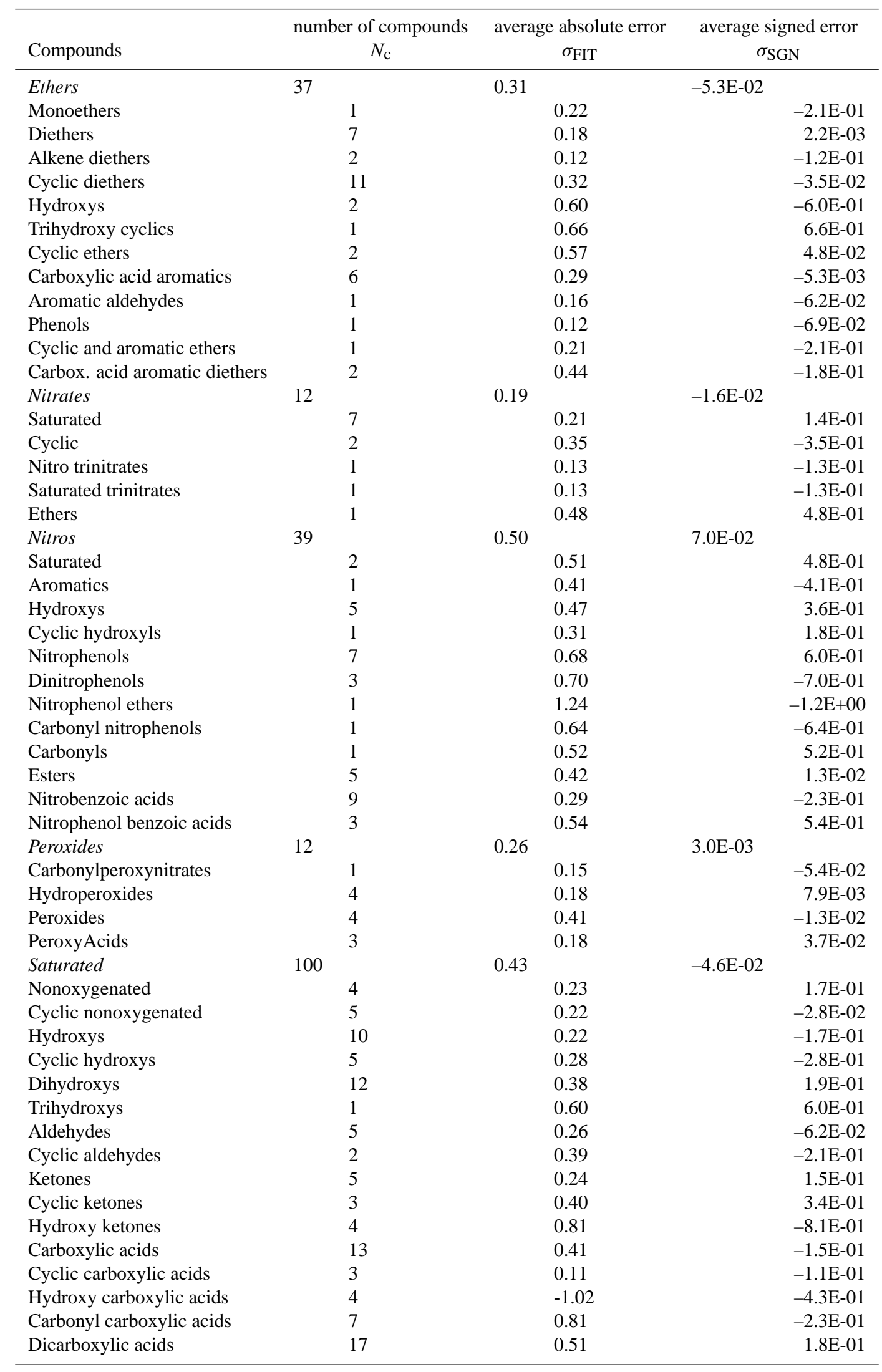


Table 8. Average standard errors $\left(\sigma_{\Delta H}\right.$ and $\left.\sigma_{\Delta H_{-} \mathrm{SGN}}\right)$ and average relative standard errors $\left(\rho_{\Delta H}\right.$ and $\left.\rho_{\Delta H_{-} \mathrm{SGN}}\right)$ in predicting $\Delta H_{\mathrm{vap}, i}$ values at $335.15 \mathrm{~K}$ for organic compounds using SIMPOL. 1 coefficients as optimized for all compounds in Tables 1 and 3.

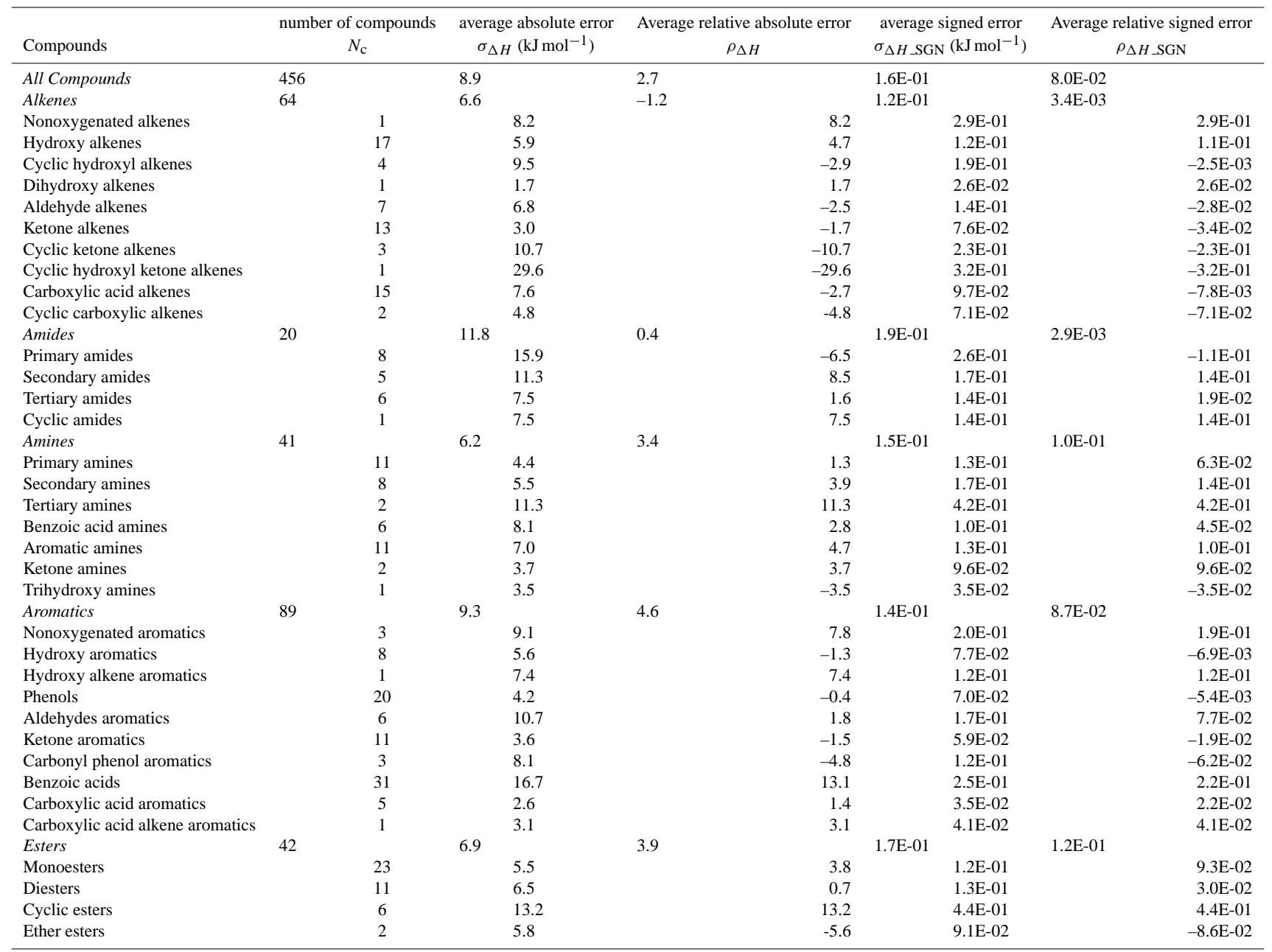

set containing $31 \times 4$ initial values) were populated randomly (though subject to the condition that the absolute value of all four terms on the right-hand side of Eq. (8) were of order unity). The mean and standard deviation of the $100 \chi^{2}$ values were 472 and 23 , respectively. The smallest of these $\chi^{2}$ was 372 .

In the second step of the optimization, the set of $B$ values giving $\chi^{2}=372$ was subjected to further refinement by running 100 additional optimizations, varying each $B$ by a random amount, with all variations restricted within $\pm 30 \%$. The mean and standard deviation of the resulting $100 \chi^{2}$ values were 332 and 3 , respectively. The smallest of the $\chi^{2}$ was 325. Further attempts to refine the coefficients did not produce any significant decrease in $\chi^{2}$. When comparing the $B$ set for $\chi^{2}=372$ to the set for $\chi^{2}=325$, the median absolute difference is $30 \%$.

\section{Results}

3.1 Fit accuracy of SIMPOL.1 with initial basis set compounds

The overall agreement between the experimental and predicted values can be assessed in terms of an absolute value form of standard error of the fit:

$$
\begin{aligned}
& \sigma_{\mathrm{FIT}}=\frac{1}{N} \sum_{i=1}^{N_{\mathrm{c}}} \sum_{j=1}^{N_{\mathrm{T}, i}}\left|\log _{10}\left(p_{\mathrm{L}, i}^{\mathrm{o}}\left(T_{j, i}\right)\right)_{\mathrm{P}}-\log _{10}\left(p_{\mathrm{L}, i}^{\mathrm{o}}\left(T_{j, i}\right)\right)_{\mathrm{E}}\right| \\
& =\frac{1}{N} \sum_{i=1}^{N_{\mathrm{c}}} \sum_{j=1}^{N_{\mathrm{T}, i}} \sigma_{\mathrm{FIT}, i}
\end{aligned}
$$

where $\left(p_{\mathrm{L}, i}^{\mathrm{o}}\left(T_{j, i}\right)\right)_{\mathrm{P}}$ is the predicted vapor pressure for $i$ at temperature $T_{j, i}$ by Eq. (6). For the basis set, $N_{\mathrm{c}}=272$ and $N=1844$ (see above), and using the set of $B$ giving $\chi^{2}=325$ yields $\sigma_{\mathrm{FIT}}=0.29$ (log units): on average, $\left(p_{\mathrm{L}, i}^{\mathrm{o}}\left(T_{j, i}\right)\right)_{\mathrm{E}}$ for 
Table 8. Continued.

\begin{tabular}{|c|c|c|c|c|c|c|}
\hline \multirow{2}{*}{$\begin{array}{l}\text { Compounds } \\
\text { Ethers }\end{array}$} & $\begin{array}{l}\text { number of compounds } \\
\qquad N_{\mathrm{c}}\end{array}$ & $\begin{array}{l}\text { average absolute error } \\
\sigma_{\Delta H}\left(\mathrm{~kJ} \mathrm{~mol}^{-1}\right)\end{array}$ & $\begin{array}{l}\text { Average relative absolute error } \\
\qquad \rho_{\Delta H}\end{array}$ & $\begin{array}{l}\text { average signed error } \\
\sigma_{\Delta H_{-} \mathrm{SGN}}\left(\mathrm{kJ} \mathrm{mol}^{-1}\right)\end{array}$ & \multicolumn{2}{|c|}{$\begin{array}{l}\text { Average relative signed error } \\
\qquad \rho_{\Delta H_{-} \mathrm{SGN}}\end{array}$} \\
\hline & 37 & 7.2 & 4.5 & $1.4 \mathrm{E}-01$ & $1.1 \mathrm{E}-01$ & \\
\hline Monoethers & 1 & 11.3 & 11.3 & 4.3E-01 & & 4.3E-01 \\
\hline Diethers & 7 & 3.5 & 2.6 & $9.7 \mathrm{E}-02$ & & $8.2 \mathrm{E}-02$ \\
\hline Alkene diethers & 2 & 3.5 & 3.5 & $9.4 \mathrm{E}-02$ & & $9.4 \mathrm{E}-02$ \\
\hline Cyclic diethers & 11 & 6.1 & 5.2 & $1.5 \mathrm{E}-01$ & & $1.4 \mathrm{E}-01$ \\
\hline Hydroxy ethers & 2 & 12.9 & 12.9 & $2.6 \mathrm{E}-01$ & & $2.6 \mathrm{E}-01$ \\
\hline Trihydroxy cyclic ethers & 1 & 21.5 & -21.5 & $1.8 \mathrm{E}-01$ & & $-1.8 \mathrm{E}-01$ \\
\hline Ether cyclic ethers & 2 & 10.5 & -2.4 & $1.8 \mathrm{E}-01$ & & $-1.9 \mathrm{E}-03$ \\
\hline Carboxylic acid aromatic ethers & 6 & 5.0 & 4.6 & $6.0 \mathrm{E}-02$ & & $5.6 \mathrm{E}-02$ \\
\hline Aromatic aldehyde ethers & 1 & 10.0 & 10.0 & $1.7 \mathrm{E}-01$ & & $1.7 \mathrm{E}-01$ \\
\hline Phenolic ethers & 1 & 7.4 & -7.4 & $1.0 \mathrm{E}-01$ & & $-1.0 \mathrm{E}-01$ \\
\hline Cyclic ether and aromatic ethers & 1 & 9.7 & 9.7 & $1.8 \mathrm{E}-01$ & & $1.8 \mathrm{E}-01$ \\
\hline Carboxylic acid aromatic diethers & 2 & 16.0 & 16.0 & $2.0 \mathrm{E}-01$ & & $2.0 \mathrm{E}-01$ \\
\hline Nitrates & 12 & 9.2 & 2.04 & $1.7 \mathrm{E}-01$ & 7.7E-02 & \\
\hline Saturated nitrates & 7 & 4.4 & -0.5 & $1.2 \mathrm{E}-01$ & & 7.4E-03 \\
\hline Cyclic nitrates & 2 & 7.0 & 7.0 & $2.5 \mathrm{E}-01$ & & $2.5 \mathrm{E}-01$ \\
\hline Nitro trinitrates & 1 & 2.4 & 2.4 & $8.9 \mathrm{E}-02$ & & 8.9E-02 \\
\hline Saturated trinitrates & 1 & 1.0 & 1.0 & 4.1E-02 & & 4.1E-02 \\
\hline Nitrate ethers & 1 & 6.5 & -6.5 & $1.2 \mathrm{E}-01$ & & $-1.2 \mathrm{E}-01$ \\
\hline Nitros & 39 & 11.0 & 4.2 & $1.6 \mathrm{E}-01$ & $7.2 \mathrm{E}-02$ & \\
\hline Saturated nitros & 2 & 7.4 & 2.3 & $1.7 \mathrm{E}-01$ & & $7.5 \mathrm{E}-02$ \\
\hline Aromatic nitros & 1 & 10.9 & 10.9 & $1.3 \mathrm{E}-01$ & & $1.3 \mathrm{E}-01$ \\
\hline Hydroxy nitros & 5 & 7.9 & -1.3 & $1.2 \mathrm{E}-01$ & & $3.2 \mathrm{E}-03$ \\
\hline Cyclic hydroxy nitros & 1 & 27.0 & -27.0 & 2.7E-01 & & $-2.7 \mathrm{E}-01$ \\
\hline Nitrophenols & 7 & 9.2 & -9.2 & $1.3 \mathrm{E}-01$ & & $-1.3 \mathrm{E}-01$ \\
\hline Dinitrophenols & 3 & 2.0 & -2.0 & 2.7E-02 & & $-2.7 \mathrm{E}-02$ \\
\hline Nitrophenol ethers & 1 & 13.1 & 13.1 & $2.6 \mathrm{E}-01$ & & 2.6E-01 \\
\hline Carbonyl nitrophenols & 1 & 3.0 & -3.0 & 4.4E-02 & & $-4.4 \mathrm{E}-02$ \\
\hline Carbonyl nitros & 1 & 4.2 & -4.2 & $7.8 \mathrm{E}-02$ & & $-7.8 \mathrm{E}-02$ \\
\hline Nitro esters & 5 & 23.3 & 23.3 & 4.1E-01 & & 4.1E-01 \\
\hline Nitrobenzoic acids & 9 & 11.3 & 11.3 & $1.5 \mathrm{E}-01$ & & $1.5 \mathrm{E}-01$ \\
\hline Nitrophenol benzoic acids & 3 & 8.7 & 8.7 & $9.6 \mathrm{E}-02$ & & $9.6 \mathrm{E}-02$ \\
\hline Peroxides & 12 & 8.6 & -1.6 & $2.0 \mathrm{E}-01$ & $2.9 \mathrm{E}-02$ & \\
\hline Carbonylperoxynitrates & 1 & 8.6 & -8.6 & $2.3 \mathrm{E}-01$ & & $-2.3 \mathrm{E}-01$ \\
\hline Hydroperoxides & 4 & 10.3 & -4.2 & $1.4 \mathrm{E}-01$ & & $1.4 \mathrm{E}-03$ \\
\hline Peroxides & 4 & 11.1 & -0.2 & $3.6 \mathrm{E}-01$ & & $1.0 \mathrm{E}-01$ \\
\hline PeroxyAcids & 3 & 3.1 & 2.5 & $7.0 \mathrm{E}-02$ & & $5.5 \mathrm{E}-02$ \\
\hline Saturated & 100 & 11.0 & 2.4 & $2.1 \mathrm{E}-01$ & $1.1 \mathrm{E}-01$ & \\
\hline Nonoxygenated & 4 & 9.6 & 9.6 & $2.8 \mathrm{E}-01$ & & $2.8 \mathrm{E}-01$ \\
\hline Cyclic nonoxygenated & 5 & 4.6 & 4.6 & $1.4 \mathrm{E}-01$ & & $1.4 \mathrm{E}-01$ \\
\hline Hydroxys & 10 & 6.6 & 6.6 & $1.4 \mathrm{E}-01$ & & $1.4 \mathrm{E}-01$ \\
\hline Cyclic hydroxys & 5 & 4.1 & 3.8 & $8.5 \mathrm{E}-02$ & & 7.9E-02 \\
\hline Dihydroxys & 12 & 4.1 & -1.2 & $5.6 \mathrm{E}-02$ & & $-9.9 \mathrm{E}-03$ \\
\hline Trihydroxys & 1 & 1.3 & -1.3 & $1.5 \mathrm{E}-02$ & & $-1.5 \mathrm{E}-02$ \\
\hline Aldehydes & 5 & 13.7 & 13.7 & 4.6E-01 & & 4.6E-01 \\
\hline Cyclic aldehydes & 2 & 22.7 & -22.7 & $3.0 \mathrm{E}-01$ & & $-3.0 \mathrm{E}-01$ \\
\hline Ketones & 5 & 3.5 & -2.7 & 7.3E-02 & & $-5.3 \mathrm{E}-02$ \\
\hline Cyclic ketones & 3 & 6.2 & -2.5 & $1.7 \mathrm{E}-01$ & & $-3.0 \mathrm{E}-02$ \\
\hline Hydroxy ketones & 4 & 9.6 & 9.6 & $2.1 \mathrm{E}-01$ & & 2.1E-01 \\
\hline Carboxylic acids & 13 & 7.0 & 1.6 & $1.2 \mathrm{E}-01$ & & $5.6 \mathrm{E}-02$ \\
\hline Cyclic carboxylic acids & 3 & 1.7 & -1.6 & 2.7E-02 & & $-2.6 \mathrm{E}-02$ \\
\hline Hydroxy carboxylic acids & 4 & 54.7 & 42.0 & $6.7 \mathrm{E}-01$ & & $6.5 \mathrm{E}-01$ \\
\hline Carbonyl carboxylic acids & 7 & 20.6 & -12.1 & $2.0 \mathrm{E}-01$ & & $-8.1 \mathrm{E}-02$ \\
\hline Dicarboxylic acids & 17 & 15.1 & -1.8 & $2.9 \mathrm{E}-01$ & & $1.3 \mathrm{E}-01$ \\
\hline
\end{tabular}

compounds in the basis set is predicted to within a factor of $\sim 2$. This is evidenced in Fig. 1, which is a plot of $\log _{10}\left(p_{\mathrm{L}, i}^{\mathrm{o}}\left(T_{j, i}\right)\right)_{\mathrm{P}}$ vs. $\log _{10}\left(p_{\mathrm{L}, i}^{\mathrm{o}}\left(T_{j, i}\right)\right)_{\mathrm{E}}$ for the initial basis set compounds at $333.15 \mathrm{~K}$, the lowest $T$ to which all of the experimentally based $p_{\mathrm{L}, i}^{\mathrm{o}}=f_{i}(T)$ expressions extended. It should be noted that although the minimum $p_{\mathrm{L}, i}^{\mathrm{o}}$ shown in Fig. 1 is $10^{-9}$ atm, there were 24 values of $p_{\mathrm{L}, i}^{\mathrm{o}}$ included in the optimization that were lower than $10^{-9}$ atm with a minimum $p_{\mathrm{L}, i}^{\mathrm{o}}$ of $7.90 \times 10^{-14}$ atm. However, these lower values were for compounds at lower temperatures, where the data is not shown on the figure.

Given the multi-functionality possessed by many of the compounds, the 13 major compound class designations used in the figures are somewhat arbitrary. The "saturated" class for example, includes all compounds lacking double bonds and aromatic rings that are not assigned to another class, and so includes simple alcohols, carbonyls, and acids. Similarly, the nitro class contains compounds having only nitro groups, but also compounds with nitro groups and hydroxyl, 
Table 9. Numbers of compounds with $d \Delta H_{\mathrm{vap}, i} / d T<0$ at $T=333.15$.

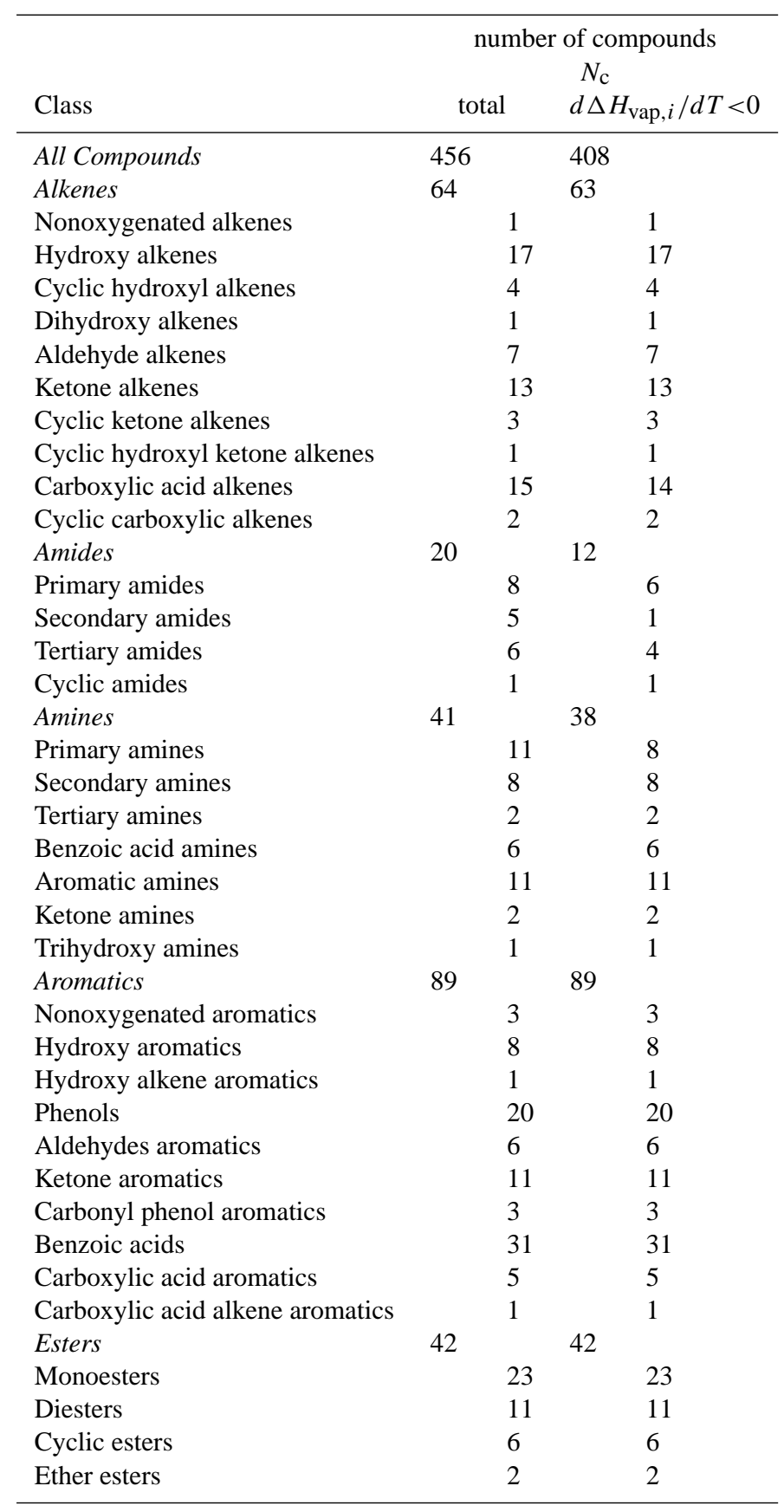

carbonyl, or acid functionality. Table 2 provides $\sigma_{\text {FIT }}$ for the initial basis set by compound class, i.e., with $N_{\mathrm{c}}$ and $N$ in Eq. (13) limited to represent the compounds within a particular class. Figure 2 provides a plot of the corresponding individual $\sigma_{\mathrm{FIT}, i}$ vs. $\log _{10}\left(p_{\mathrm{L}, i}^{\mathrm{o}}\left(T_{j, i}\right)\right)_{\mathrm{E}}$ for $333.15 \mathrm{~K}$.

An estimate of the method bias towards over- or underfitting the $p_{\mathrm{L}, i}^{\mathrm{o}}$ is obtained by a variation of Eq. (13) that does not use absolute values:

$$
\begin{aligned}
& \sigma_{\mathrm{SGN}}=\frac{1}{N} \sum_{i=1}^{N_{\mathrm{c}}} \sum_{j=1}^{N_{\mathrm{T}, i}}\left(\log _{10} p_{\mathrm{L}, i}^{\mathrm{o}}\left(T_{j, i}\right)_{\mathrm{P}}-\log _{10} p_{\mathrm{L}, i}^{\mathrm{o}}\left(T_{j, i}\right)_{\mathrm{E}}\right) \\
& =\frac{1}{N} \sum_{i=1}^{N_{\mathrm{c}}} \sum_{j=1}^{N_{\mathrm{T}, i}} \sigma_{\mathrm{SGN}, i}
\end{aligned}
$$


Table 9. Continued.

\begin{tabular}{|c|c|c|}
\hline \multirow[b]{2}{*}{ Class } & \multicolumn{2}{|c|}{$\begin{array}{l}\text { number of compounds } \\
\qquad N_{\mathrm{c}}\end{array}$} \\
\hline & total & $d \Delta H_{\mathrm{vap}, i} / d T<0$ \\
\hline Ethers & 37 & 36 \\
\hline Monoethers & 1 & 1 \\
\hline Diethers & 7 & 7 \\
\hline Alkene diethers & 2 & 2 \\
\hline Cyclic diethers & 11 & 10 \\
\hline Hydroxy ethers & 2 & 2 \\
\hline Trihydroxy cyclic ethers & 1 & 1 \\
\hline Ether cyclic ethers & 2 & 2 \\
\hline Carboxylic acid aromatic ethers & 6 & 6 \\
\hline Aromatic aldehyde ethers & 1 & 1 \\
\hline Phenolic ethers & 1 & 1 \\
\hline Cyclic ether and aromatic ethers & 1 & 1 \\
\hline Carboxylic acid aromatic diethers & 2 & 2 \\
\hline Nitrates & 12 & 12 \\
\hline Saturated nitrates & 7 & 6 \\
\hline Cyclic nitrates & 2 & 2 \\
\hline Nitro trinitrates & 1 & 0 \\
\hline Saturated trinitrates & 1 & 0 \\
\hline Nitrate ethers & 1 & 1 \\
\hline Nitros & 39 & 32 \\
\hline Saturated nitros & 2 & 2 \\
\hline Aromatic nitros & 1 & 1 \\
\hline Hydroxy nitros & 5 & 1 \\
\hline Cyclic hydroxy nitros & 1 & 1 \\
\hline Nitrophenols & 7 & 7 \\
\hline Dinitrophenols & 3 & 3 \\
\hline Nitrophenol ethers & 1 & 1 \\
\hline Carbonyl nitrophenols & 1 & 1 \\
\hline Carbonyl nitros & 1 & 1 \\
\hline Nitro esters & 5 & 2 \\
\hline Nitrobenzoic acids & 9 & 9 \\
\hline Nitrophenol benzoic acids & 3 & 3 \\
\hline Peroxides & 12 & 8 \\
\hline Carbonylperoxynitrates & 1 & 1 \\
\hline Hydroperoxides & 4 & 1 \\
\hline Peroxides & 4 & 4 \\
\hline PeroxyAcids & 3 & 2 \\
\hline Saturated & 100 & 76 \\
\hline Nonoxygenated & 4 & 4 \\
\hline Cyclic nonoxygenated & 5 & 5 \\
\hline Hydroxy & 10 & 10 \\
\hline Cyclic hydroxy & 5 & 5 \\
\hline Dihydroxy & 12 & 6 \\
\hline Trihydroxy & 1 & 0 \\
\hline Aldehyde & 5 & 5 \\
\hline Cyclic aldehyde & 2 & 2 \\
\hline Ketone & 5 & 5 \\
\hline Cyclic ketone & 3 & 3 \\
\hline Hydroxy ketone & 4 & 4 \\
\hline Carboxylic acid & 13 & 9 \\
\hline Cyclic carboxylic acid & 3 & 3 \\
\hline Hydroxy carboxylic acid & 4 & 3 \\
\hline Carbonyl carboxylic acid & 7 & 2 \\
\hline Dicarboxylic acid & 17 & 10 \\
\hline
\end{tabular}




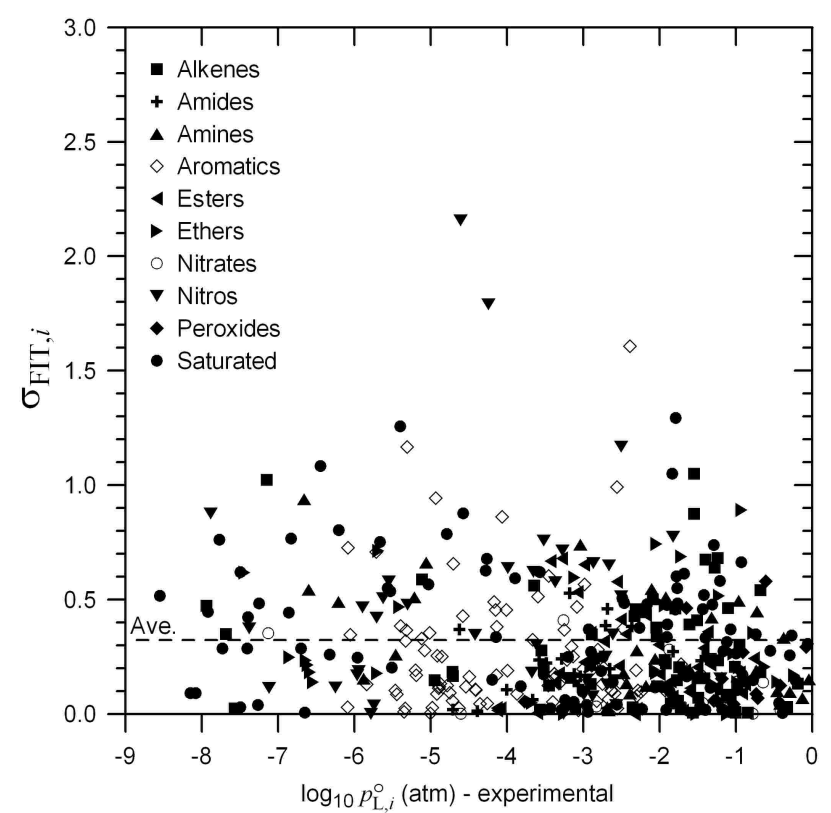

Fig. 8. $\sigma_{\mathrm{FIT}, i}$ at $333.15 \mathrm{~K}$ for all compounds calculated as defined in Eq. (13) plotted vs. experimentally derived $\log _{10} p_{\mathrm{L}, i}^{\mathrm{o}}$ (333.15). Predicted $p_{\mathrm{L}, i}^{\mathrm{o}}$ values used in calculating the $\sigma_{\mathrm{FIT}, i}$ are based on the final optimization using all of the compounds.

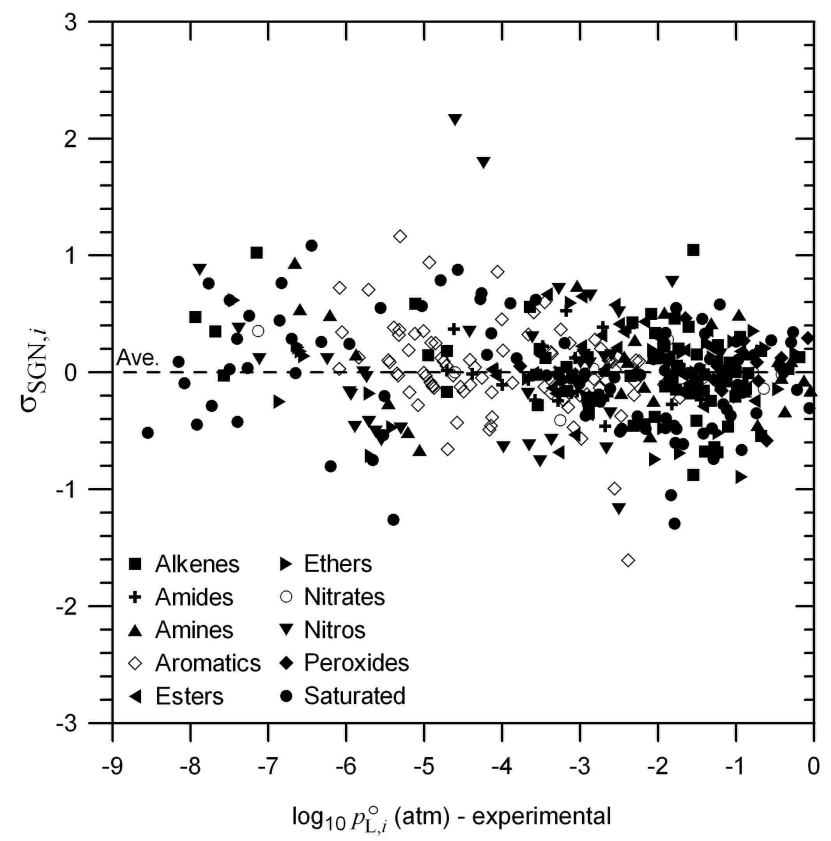

Fig. 9. $\sigma_{\mathrm{SGN}, i}$ at $333.15 \mathrm{~K}$ for all compounds calculated as defined in Eq. (14) plotted vs. experimentally derived $\log _{10} p_{\mathrm{L}, i}^{\mathrm{o}}(333.15)$. Predicted $p_{\mathrm{L}, i}^{\mathrm{o}}$ values used in calculating the $\sigma_{\mathrm{SGN}, i}$ are based on the final optimization using all of the compounds.

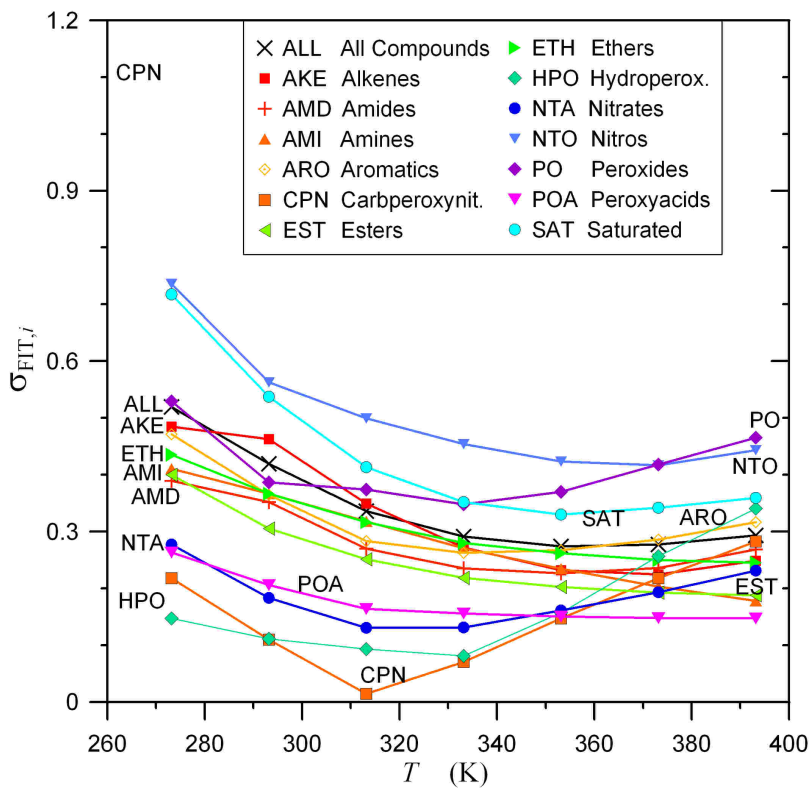

Fig. 10. $\sigma_{\mathrm{FIT}}$ as a function of $T$ and compound class. Predicted $p_{\mathrm{L}, i}^{\mathrm{o}}$ values used in calculating the $\sigma_{\mathrm{FIT}}$ are based on the final optimization using all of the compounds.

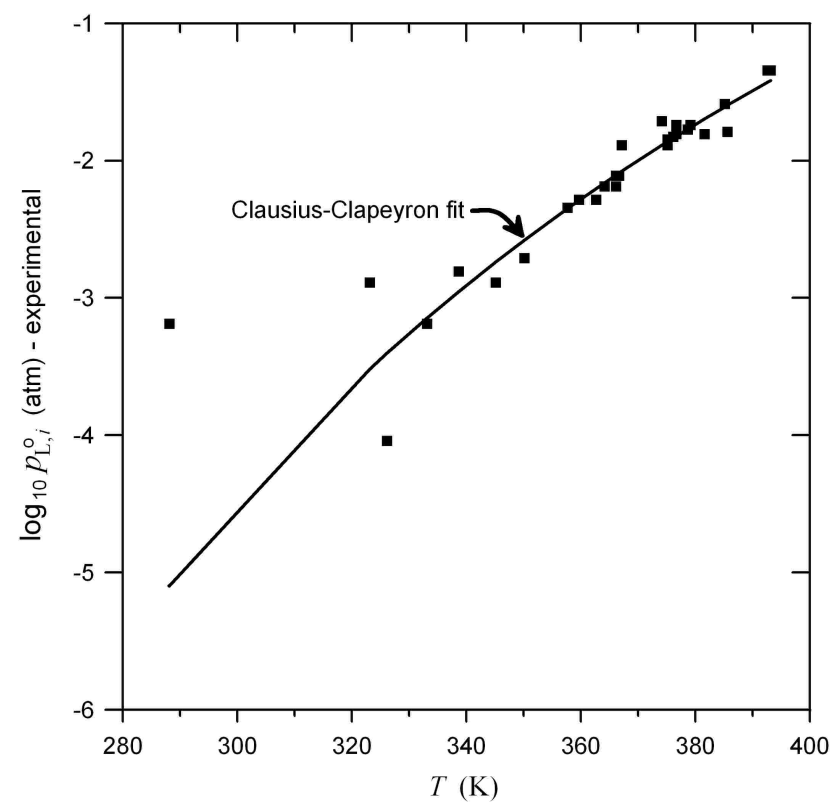

Fig. 11. Experimental $p_{\mathrm{L}}^{\mathrm{o}}$ data for nitroethanol from the Beilstein PlusReactions Database BS070100PR (http://www.beilstein.com/) showing increase in uncertainty in data as temperature decreases. Solid line is fit to the data. 


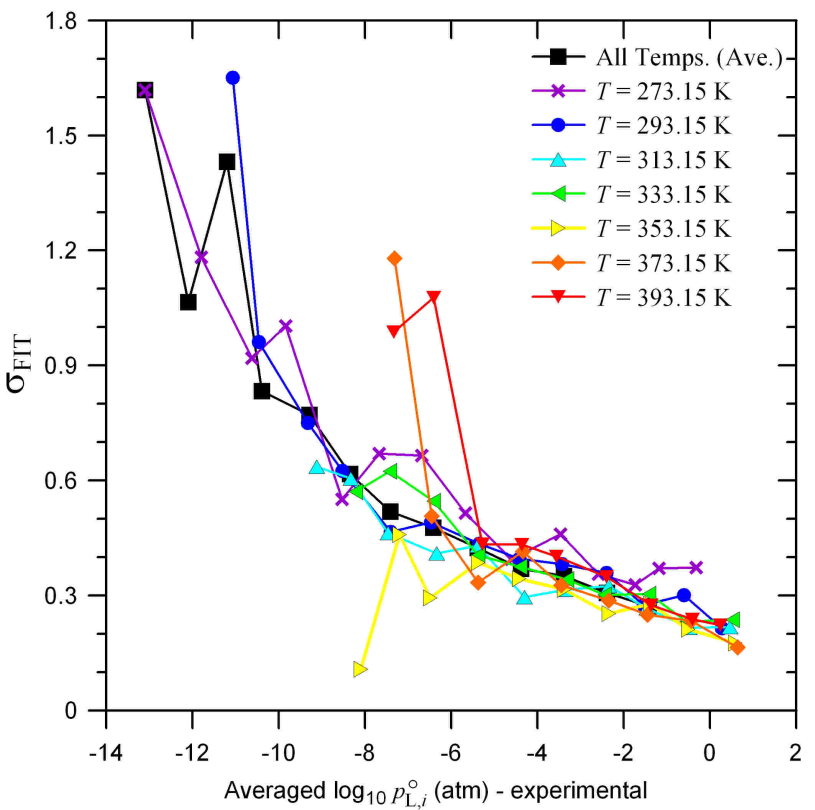

Fig. 12. The standard error $\sigma_{\text {FIT }}$ at each $T$ was calculated by sorting all compounds by increasing $p_{\mathrm{L}}^{\mathrm{o}}$, and then computing the average $\sigma_{\text {FIT }}$ values and $p_{\mathrm{L}}^{\mathrm{o}}$ values over decade ranges. E.g., at $333.15 \mathrm{~K}$, each $x$-coordinate is the $\log _{10}$ value of the $p_{\mathrm{L}}^{\mathrm{o}}$ average for all compounds with $1 \times 10^{-6} \mathrm{~atm} \leq p_{\mathrm{L}}^{\mathrm{o}}<1 \times 10^{-5}$ atm at that $T$, and the $y$ coordinate is the average of the corresponding $\sigma_{\mathrm{FIT}, i}$ values.

For the initial basis set of compounds, the set of $B$ producing $\chi^{2}=325$ gives $\sigma_{\mathrm{SGN}}=1.4 \times 10^{-3}$ (log units). This indicates that as averaged over all 272 initial basis set compounds and seven temperatures, there is no significant bias in the fitting; the $\sigma_{\mathrm{SGN}}$ values in Table 2 indicate that this result extends down to each of the 13 major compound classes considered. Figure 3 provides a plot of the corresponding individual $\sigma_{\mathrm{SGN}, i}$ vs. $\log _{10}\left(p_{\mathrm{L}, i}^{\mathrm{o}}\left(T_{j, i}\right)\right)_{\mathrm{E}}$ for $333.15 \mathrm{~K}$.

\subsection{Method validation of SIMPOL.1 with a test set of com- pounds}

The ability of the set of $B$ coefficients producing $\chi^{2}=325$ to predict values of $\left(p_{\mathrm{L}, i}^{\mathrm{o}}\left(T_{j, i}\right)\right)_{\mathrm{E}}$ for compounds outside the initial basis set was examined using a test set of 184 compounds (Table 3) with $N=1245\left(p_{\mathrm{L}, i}^{\mathrm{o}}\left(T_{j, i}\right)\right)_{\mathrm{E}}$ values chosen to span the range of volatilities and functionalities of the compounds in the basis set; the results are given in Figs. 4-6 and Table 4. The $p_{\mathrm{L}, i}^{\mathrm{o}}=f_{i}(T)$ expressions used in evaluation of the $\left(p_{\mathrm{L}, i}^{\mathrm{o}}\left(T_{j, i}\right)\right)_{\mathrm{E}}$ are provided in the supplementary online materials http://www.atmos-chem-phys.net/ 8/2773/2008/acp-8-2773-2008-supplement.pdf. Averaged over all test set compounds, $\sigma_{\mathrm{FIT}}=0.45$, and $\sigma_{\mathrm{SGN}}=-0.071$ : the average prediction error is a factor of $\sim 3$, and there is no significant overall bias. Table 4 gives $\sigma_{\mathrm{FIT}}$ and $\sigma_{\mathrm{SGN}}$ values for the test compounds when $N_{\mathrm{c}}$ and $N$ are limited to represent the compounds within a particular compound class.

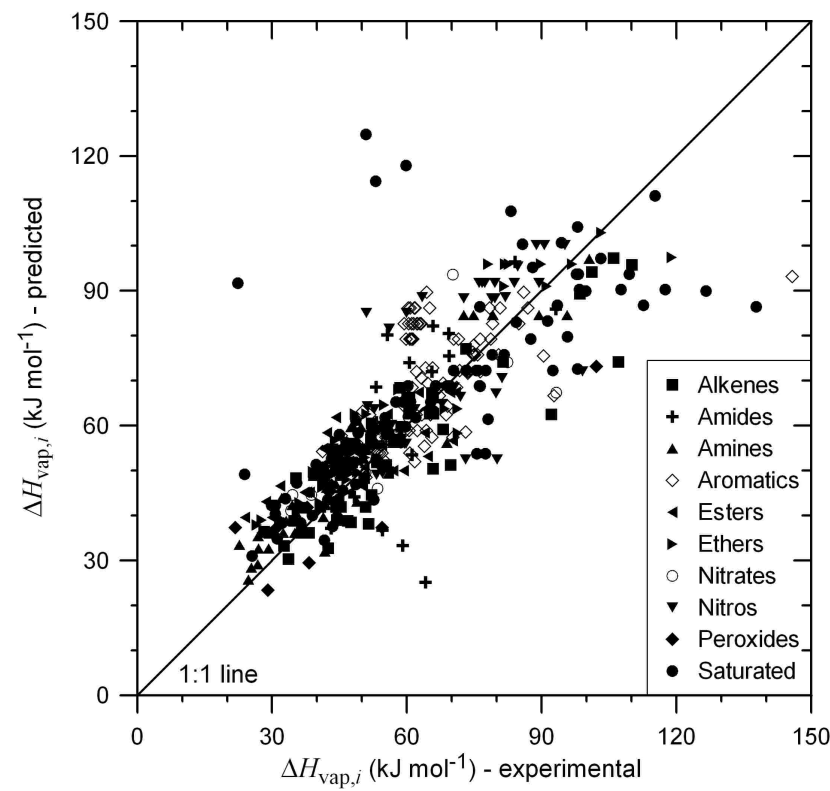

Fig. 13. $\Delta H_{\mathrm{vap}, i}$ at $333.15 \mathrm{~K}$ based on Eq. (10) and the final coefficients in Table 5, vs. $\Delta H_{\mathrm{vap}, i}$ at $333.15 \mathrm{~K}$ based on Eq. (9) and the experimentally based $p_{\mathrm{L}, i}^{\mathrm{o}}=f_{i}(T)$ functions.

Overall, given the wide range of compounds in the test set, SIMPOL. 1 does well in predicting $\left(p_{\mathrm{L}, i}^{\mathrm{o}}\left(T_{j, i}\right)\right)_{\mathrm{E}}$. However, the individual compounds for which the performance is appears to be poor bear some discussion. In the case of the nitro class, $\sigma_{\mathrm{FIT}}$ and $\sigma_{\mathrm{SGN}}$ are 1.0 and 0.40 , respectively. These ostensibly poor results are driven by: 1) the small number of nitro compounds in the test set; and 2) large apparent errors for only two of the nitro compounds, 3-nitrophenol and 4nitrophenol $\left(\sigma_{\mathrm{FIT}, i}=2.64\right.$ and 2.24 , respectively). The cause of the poor performance for 3-nitrophenol and 4-nitrophenol is not clear. By comparison, for 2-nitrophenol (which is in the initial basis set), $\sigma_{\mathrm{FIT}, i}$ is better $(0.42)$. Thus, there might be a large effect of meta and para substitution on $p_{\mathrm{L}}^{\mathrm{o}}$ for nitrophenols. Alternatively, it is possible that the $\left(p_{\mathrm{L}, i}^{\mathrm{o}}\left(T_{j, i}\right)\right)_{\mathrm{E}}$ values for 3-nitrophenol and 4-nitrophenol are in error. Indeed, it is undoubtedly true that some of the experimentally based $p_{\mathrm{L}, i}^{\mathrm{o}}=f_{i}(T)$ expressions suffer from significant error: numerous prior parameter prediction studies have identified experimental data that likely are in error, e.g., see the comments by Rathbun (1987) on the likelihood of errors in the $p_{\mathrm{L}}^{\mathrm{o}}$ data of Stull (1947) for 2-pentanone and other similar ketones.

Besides compounds containing the nitro group, method performance appears to be relatively poor for some compounds in the saturated class, the aromatic class, and some compounds in the ether class. For the saturated class, $\sigma_{\text {FIT }}=0.66$, due mainly to 2-hydroxy-2-methyl-3-hexanone, 2-ethyl-hexanoic acid, norpinic acid, and the three longchain hydroxyl acids. When these six compounds are removed, $\sigma_{\text {FIT }}$ for the remaining 32 compounds is lowered to 
0.51 , and the method may be viewed as performing relatively well. Given their relatively simple structures, (i.e., the absence of likely effects from higher order groups), errors in some of the $\left(p_{\mathrm{L}, i}^{\mathrm{o}}\left(T_{j, i}\right)\right)_{\mathrm{E}}$ values for compounds in the saturated class seem possible. This is especially the case for the hydroxyl acids, where at $T=273.15 \mathrm{~K}$ SIMPOL. 1 underestimates the measured $\left(p_{\mathrm{L}, i}^{\mathrm{o}}\left(T_{j, i}\right)\right)_{\mathrm{E}}$ by over 3 orders of magnitude. However, SIMPOL.1 overestimates the measured $\left(p_{\mathrm{L}, i}^{\mathrm{o}}\left(T_{j, i}\right)\right)_{\mathrm{E}}$ by a factor of at least 10 for $T=273.15 \mathrm{~K}$, suggesting that the dependence of $\left(p_{\mathrm{L}, i}^{\mathrm{o}}\left(T_{j, i}\right)\right)_{\mathrm{E}}$ on $T$ is very different from that predicted overall by SIMPOL.1. For the ethers, the overall error is relatively low, $\sigma_{\text {FIT }}=0.42$, with a relatively large bias, $\sigma_{\mathrm{SGN}}=-0.25$, but there are not consistent patterns in the results that explain the relatively large bias. However, for trans-2,2,4,6-tetramethyl-1,3-dioxane, for its set of $T_{j, i}$ values, $\sigma_{\mathrm{FIT}, i}$ averages 1.2 ; removing this compound from the average for the ether class dramatically reduces the magnitudes of $\sigma_{\mathrm{FIT}}$ and $\sigma_{\mathrm{SGN}}$ for the ethers to 0.34 and -0.15 , respectively.

3.3 Final coefficients for SIMPOL.1 and associated error estimates for $p_{\mathrm{L}}^{\mathrm{o}}$ values

In the determination of the final set of $B$ coefficients, the basis set compounds in Table 1 were combined with the test set compounds in Table 3. For this combined set (456 compounds), the set of $B$ coefficients determined using the initial basis set gives $\chi^{2}=855$. For each of 100 subsequent optimization runs, the initial value of each $B$ coefficient was taken as the final value determined using the initial basis set modified randomly by at most $\pm 30 \%$. The lowest $\chi^{2}$ value thus obtained was 728 (mean=736, standard deviation=6). Further optimization attempts did not succeed in lowering $\chi^{2}$.

Table 5 gives the final $B$ coefficients giving $\chi^{2}=736$. Table 6 gives the values of the $b_{k}(T)$ at $T=293.15$ : at that $T$, adding one carbon, carboxylic acid, alkyl hydroxyl, ketone, or aldehyde groups alters $\log _{10} p_{\mathrm{L}, i}^{\mathrm{o}}$ by $-0.438,-3.58$, $-2.23,-0.935$, and -1.35 , respectively. For comparison, Table 6 also provides the corresponding values of $\tau_{k}(293.15)$ from Capouet and Müller (2006); these are generally similar to the $b_{k}(293.15)$ determined here. For the carboxylic acid, primary hydroxyl, and carbonyl (i.e., ketone or aldehyde) groups, Capouet and Müller (2006) give $\tau_{k}(293.15)=-3.10$, -2.76 , and -0.91 .

Consider the transformation of cyclohexene to adipic acid, an example that has historical significance in the evolution of the understanding of the formation of secondary OPM in the atmosphere (Haagen-Smit, 1952). For cyclohexene, $v_{0}=$ $1, v_{1}=6, v_{4}=1$, and $v_{5}=1$, and by Eq. (6) and the values in Table 6, SIMPOL.1 predicts $\log _{10} p_{\mathrm{L}}^{\mathrm{o}}(293.15)=-0.94$. For adipic acid, $v_{0}=1, v_{1}=6$, and $v_{10}=2$, and SIMPOL. 1 predicts $\log _{10} p_{\mathrm{L}}^{\mathrm{o}}(293.15)=-7.99$. Overall, for cyclohexene $\rightarrow$ adipic acid, the SIMPOL.1 method provides a simple parameterization for quantifying how addition of two $\mathrm{COOH}$ groups $\left(b_{10}=-3.58\right.$ at $\left.293.15 \mathrm{~K}\right)$ causes a seven order magnitude change in volatility. The $\log _{10} p_{\mathrm{L}}^{\mathrm{o}}(293.15)$ values derived using SIMPOL.1 may be compared with experimental values as follows. For cyclohexene, data in Lister (1941), Meyer and Hotz (1973) and Steele et al. (1996) yield the Antoine fit $\log _{10} p_{\mathrm{L}}^{\mathrm{o}}(T)=4.814-(1713 /(T+0.04870))$, which gives $\log _{10} p_{\mathrm{L}}^{\mathrm{O}}(T)=-1.08$ at $293.15 \mathrm{~K}$. For adipic acid, when the $p_{\mathrm{S}}^{\mathrm{o}}(T)$ (sublimation) data of Davies and Thomas (1960), Tao and McMurray (1989), Chattopadhyay and Zieman (2005), and Cappa et al. (2007) are combined with the entropy of fusion data of Roux et al. (2005) and averaged with sub-cooled liquid vapor pressures from Bilde et al. (2003), the resulting value for $\log _{10} p_{\mathrm{L}}^{\mathrm{o}}$ is -8.49 at $293.15 \mathrm{~K}$.

Figure $7 \mathrm{a}$ provides a plot of $\log _{10}\left(p_{\mathrm{L}, i}^{\mathrm{o}}\left(T_{j, i}\right)\right)_{\mathrm{P}}$ vs. $\log _{10}\left(p_{\mathrm{L}, i}^{\mathrm{o}}\left(T_{j, i}\right)\right)_{\mathrm{E}}$ for all compounds at $T=333.15 \mathrm{~K}$ and Fig. $7 \mathrm{~b}$ is a plot of $\log _{10}\left(p_{\mathrm{L}, i}^{\mathrm{o}}\left(T_{j, i}\right)\right)_{\mathrm{P}}$ vs. $\log _{10}\left(p_{\mathrm{L}, i}^{\mathrm{o}}\left(T_{j, i}\right)\right)_{\mathrm{E}}$ for all compounds at all seven temperatures showing the full lower volatility range of the dataset; Figs. 8 and 9 provide corresponding plots of $\sigma_{\mathrm{SGN}, i}$ and $\sigma_{\mathrm{FIT}, i}$ vs. $\log _{10}\left(p_{\mathrm{L}, i}^{\mathrm{o}}\left(T_{j, i}\right)\right)_{\mathrm{E}}$ except in the interest of brevity the data in Figs. 8 and 9 are shown for $T=333.15 \mathrm{~K}$ only. Table 7 provides $\sigma_{\mathrm{SGN}}$ and $\sigma_{\mathrm{FIT}}$ values by compound class and sub-class. All $\sigma_{\mathrm{SGN}}$ values for the major classes are low (no significant biases). However, among the compounds containing the nitro group, as noted above, $p_{\mathrm{L}}^{\mathrm{o}}$ is predicted poorly for 3-nitrophenol and 4-nitrophenol. When these two compounds are excluded, $\sigma_{\text {FIT }}$ for the nitro class is reduced from 0.50 to 0.42 , but even so prediction for this class seems problematical. As discussed above, this may be due to complexities in the effects of structure on $p_{\mathrm{L}}^{\mathrm{o}}$ with nitro-containing compounds, or accuracy problems with the experimental data.

Figure 10 shows $\sigma_{\text {FIT }}$ at various $T$ by major compound class. For some classes, e.g., amides and peroxides, the mean error is least for $T$ values in the center of the fitted range, and larger at both $T<300 \mathrm{~K}$ and $T>360 \mathrm{~K}$. This type of parabolic behavior in the error is typical of least-squares fitting carried out over a specific data range for the independent variable. The relatively larger errors at lower $T$ for all classes are likely exacerbated due to the increase in experimental difficulty at low $p_{\mathrm{L}}^{\mathrm{o}}$. Evidence of this difficulty at low $p_{\mathrm{L}}^{\mathrm{o}}$ is shown in Fig. 11 using data for nitroethanol. Fig. 12 plots $\sigma_{\text {FIT }}$ vs. $\log _{10}\left(p_{\mathrm{L}, i}^{\mathrm{o}}\left(T_{j, i}\right)\right)_{\mathrm{E}}$, again showing the general tendency in the error to increase with decreasing $\log _{10}\left(p_{\mathrm{L}, i}^{\mathrm{o}}\left(T_{j, i}\right)\right)_{\mathrm{E}}$. The increase in $\sigma_{\text {FIT }}$ with decreasing $p_{\mathrm{L}}^{\mathrm{o}}$ is most likely a combination of the relatively small number of data points at low vapor pressure, the increase in experimental error with decreasing volatility, and the parabolic error profile for a least-squares type of approach.

3.4 $\Delta H_{\mathrm{vap}, i}$ prediction using SIMPOL.1 with final coefficients

Values of $\Delta H_{\mathrm{vap}, i}$ may be predicted using Eq. (10) and the final $B$ coefficients in Table 5. Figure 13 shows 
predicted values of $\Delta H_{\mathrm{vap}, i}$ at $T=333.15 \mathrm{~K}$ vs. experimentally based values derived by consideration of the experimental $p_{\mathrm{L}, i}^{\mathrm{o}}=f_{i}(T)$ functions and Eq. (9). Table 8 summarizes the quality of the predictions at $T=333.15 \mathrm{~K}$ based on the following un-normalized $(\sigma)$ and normalized (i.e., relative, $\rho$ ) error estimates, with each in absolute value and signed form:

$$
\begin{aligned}
& \sigma_{\Delta H}=\frac{1}{N} \sum_{i}\left|\left(\Delta H_{\mathrm{vap}, i}\right)_{\mathrm{P}}-\left(\Delta H_{\mathrm{vap}, i}\right)_{\mathrm{E}}\right| \\
& \sigma_{\Delta H_{-} \mathrm{SGN}}=\frac{1}{N} \sum_{i}\left(\left(\Delta H_{\mathrm{vap}, i}\right)_{\mathrm{P}}-\left(\Delta H_{\mathrm{vap}, i}\right)_{\mathrm{E}}\right) \\
& \rho_{\Delta H}=\frac{1}{N} \sum_{i}\left|\frac{\left(\Delta H_{\mathrm{vap}, i}\right)_{\mathrm{P}}-\left(\Delta H_{\mathrm{vap}, i}\right)_{\mathrm{E}}}{\left(\Delta H_{\mathrm{vap}, i}\right)_{\mathrm{E}}}\right| \\
& \rho_{\Delta H_{-} \mathrm{SGN}}=\frac{1}{N} \sum_{i}\left(\frac{\left(\Delta H_{\mathrm{vap}, i}\right)_{\mathrm{P}}-\left(\Delta H_{\mathrm{vap}, i}\right)_{\mathrm{E}}}{\left(\Delta H_{\mathrm{vap}, i}\right)_{\mathrm{E}}}\right)
\end{aligned}
$$

For all compounds, $\sigma_{\Delta H}=8.9 \mathrm{~kJ} \mathrm{~mol}^{-1}$, $\sigma_{\Delta H_{-} \mathrm{SGN}}=2.7 \mathrm{~kJ} \mathrm{~mol}^{-1}, \quad \rho_{\Delta H}=0.16 \quad$ (i.e., $16 \%$ ), and $\rho_{\Delta H_{-} \mathrm{SGN}}=0.080$ (i.e., $8 \%$ ). Overall, the fit is reasonably good, especially considering that the fitted quantity was not $\Delta H_{\mathrm{vap}, i}$ but rather the underlying $p_{\mathrm{L}, i}^{\mathrm{o}}(T)$ functionalities.

3.5 Temperature dependence of $\Delta H_{\mathrm{vap}, i}$ using SIMPOL.1 with final coefficients

As noted above, theoretical considerations indicate that $d \Delta H_{\mathrm{vap}, i} / d T<0$ for any real compound below its critical temperature $T_{c, i}$. Examination of values returned by Eq. (10) with Eq. (11) indicate that while imperfect, the results are encouraging in this regard, with 408 of the 456 compounds considered returning $d \Delta H_{\mathrm{vap}, i} / d T<0$ for $T=335.15 \mathrm{~K}$. The results by compound class and sub-class are given in Table 9 .

At any given $T<T_{c, i}$, though we know that $d \Delta H_{\mathrm{vap}, i}(T) / d T<0$ (see above), this does not require for any particular group $k$ that $d \Delta h_{\mathrm{vap}, k}(T) / d T<0$, only that the $v_{k, i}$ - weighted sum is negative. However, since all $v_{k, i} \geq 0$, by Eq. (11), at least some fraction of the structurally important groups must give $d \Delta h_{\mathrm{vap}, k}(T) / d T<0$. Table 6 gives the sign of the $d \Delta h_{\mathrm{vap}, k}(T) / d T$ values at 293.15 K for the SIMPOL.1 groups based on Eq. (11) and the $B$ values in Table 5. Importantly, for the carbon group $(k=1), d \Delta h_{\mathrm{vap}, k}(T) / d T<0$. This result is important in causing $d \Delta H_{\mathrm{vap}, i}(T) / d T<0$ to be predicted for many of the compounds in Tables 1 and 3 .

For the method of Capouet and Müller (2006), taking the derivative of Eq. (3) with respect to (1/T) and consideration of Eq. (9) yields

$$
\Delta H_{\mathrm{vap}, i}(T)=\Delta H_{\mathrm{vap}, \mathrm{hc}-i}(T)-2.303 R \sum_{k} v_{k, i} \frac{d \tau_{k}(T)}{d(1 / T)}
$$

and

$$
\begin{aligned}
& \frac{d \Delta H_{\mathrm{vap}, i}(T)}{d T}=\frac{d \Delta H_{\mathrm{vap}, \mathrm{hc}-i}(T)}{d T} \\
& -2.303 R \sum_{k} v_{k, i} \frac{d}{d T} \frac{d \tau_{k}(T)}{d(1 / T)}
\end{aligned}
$$

The analogous expressions for the SIMPOL.1 representation are Eqs. (10) and (11), respectively.

The functionality selected for the $b_{k}(T)$ as fitted by Capouet and Müller (2006) is $\tau_{k}(T)=\alpha_{k}+\beta_{k} T$, giving $d \tau_{k}(T) / d(1 / T)=-\beta_{k} T^{2}$ and $(d / d T) d \tau_{k}(T) / d(1 / T)=-2 \beta_{k} T$. In the fitting results reported by Capouet and Müller (2006), all $\beta_{k}>0$. Thus in that fitting, the role of forcing $d \Delta H_{\mathrm{vap}, i}(T) / d T<0$ must then be borne entirely by $d \Delta H_{\mathrm{vap}, \mathrm{hc}-i}(T) / d T$. This is not possible for any real compound $i$. The latter derivative is only capable of bringing $\Delta H_{\mathrm{vap}, \mathrm{hc}-i}(T)$ to zero, and for the groups considered by Capouet and Müller (2006), $\Delta H_{\mathrm{vap}, i}(T)>\Delta H_{\mathrm{vap}, h c-i}(T)$. Caution should therefore accompany use of the temperature dependencies given for the $\tau_{k}$ in Capouet and Müller (2006).

Overall, regardless of the $p_{\mathrm{L}}^{\mathrm{o}}(T)$ prediction method used when modeling the atmospheric behavior of a compound over a particular $T$ interval, when it is correctly predicted over the entire interval that $d \Delta H_{\mathrm{vap}, i} / d T<0$, then the $T$ dependence given by Eq. (10) may be used. However, when $d \Delta H_{\mathrm{vap}, i} / d T>0$ over some portion of the $T$ interval of interest, $\Delta H_{\mathrm{vap}, i}$ should be evaluated at the central $T$ and then assumed to remain constant over the entire interval.

\section{Conclusions}

A simple group contribution method has been developed that allows prediction of $p_{\mathrm{L}, i}^{\mathrm{o}}$ and $\Delta H_{\mathrm{vap}, i}$ values based on straightforward molecular structure considerations. Extensive error analyses for both parameters provide a detailed understanding of the reliability of the estimates by compound class and sub-class.

One of the implications of this work is related to the information in Figs. 10, 11, and 12. There is an obvious increase in error of the fit at low vapor pressures and temperatures. The reasons for this are related to the difficulty of making accurate measurements of $p_{\mathrm{L}, i}^{\mathrm{o}}$ for low temperatures and pressures. Improvement in vapor pressure estimation techniques, especially for compounds with $p_{\mathrm{L}, i}^{\mathrm{o}}<10^{-10}$ atm will require additional empirical data.

Acknowledgements. This work was supported by National Science Foundation Grant ATM-0513492, by the Electric Power Research Institute, and by the Cooley Family Fund for Critical Research of the Oregon Community Foundation.

Edited by: M. Kulmala

\section{References}

Asher, W. E., Pankow, J. F., Erdakos, G. B., and Seinfeld, J. H.: Estimating the vapor pressures of multi-functional oxygencontaining organic compounds using group contribution methods, Atmos. Environ., 36, 1483-1498, 2002. 
Asher, W. E. and Pankow J. F.: Vapor pressure prediction for alkenoic and aromatic organic compounds by a UNIFAC-based group contribution method, Atmos. Environ., 40, 3588-3600, 2006.

Banerjee, T., Singh, M .K., and Khanna, A.: Prediction of binary VLE for imidazolium based ionic liquid systems using COSMORS, Ind. Eng. Chem. Res., 45, 3207-3219, 2006.

Barsanti, K. C. and Pankow, J. F.: Thermodynamics of the formation of atmospheric organic particulate matter by accretion reactions, 1. Aldehydes and ketones, Atmos. Environ., 38, 43714382, 2004.

Barsanti, K. C. and Pankow, J. F.: Thermodynamics of the formation of atmospheric organic particulate matter by accretion reactions, 2. Dialdehydes, methylglyoxal, and diketones, Atmos. Environ., 39, 6597-6607, 2005.

Barsanti, K. C. and Pankow, J. F.: Thermodynamics of the formation of atmospheric organic particulate matter by accretion reactions. 3. Carboxylic and dicarboxylic acids, Atmos. Environ., 40, 6676-6686, 2006.

Bilde, M., Svenningsson, B., Monster, J., and Rosenorn, T.: Evenodd alternation of evaporation rates and vapor pressures of C3C9 dicarboxylic acid aerosols, Environ. Sci. Technol., 37, 13711378, 2003.

Cappa, C. D., Lovejoy, E. R., and Ravishankara, A. R.: Determination of evaporation rates and vapor pressures of very low volatility compounds: A study of the C4-C10 and $\mathrm{C} 12$ dicarboxylic acids, J. Phys. Chem., 111, 3099-3109.

Capouet, M. and Müller, J.-F.: A group contribution method for estimating the vapour pressures of $\alpha$-pinene oxidation products, Atmos. Chem. Phys., 6, 1455-1467, 2006, http://www.atmos-chem-phys.net/6/1455/2006/.

Chattopadhyay, S. and Zieman, P. J.: Vapor pressures of substituted and unsubstituted monocarboxylic and dicarboxylic acids measured using an improved thermal desorption particle beam mass spectrometry method, Aerosol Sci. Technol., 39, 10851100, 2005.

Davies, M. and Thomas, G. H.: Lattice energies, infrared spectra, and possible cyclization of some dicarboxylic acids, Trans. Faraday Soc., 56, 185-192, 1960.

Diedenhofen, M., Klamt, A., Marshd, K., and Schäfere, A.: Prediction of the vapor pressure and vaporization enthalpy of 1-n-alkyl-3-methylimidazolium-bis-(trifluoromethanesulfonyl) amide ionic liquids, Phys. Chem. Chem. Phys. 9, 4653-4656, 2007.

Haagen-Smit, A. J.: Chemistry and physiology of Los Angeles smog, J. Ind. Eng. Chem., 44, 1342-1346, 1952.

Hansen, H. K., Rasmussen, P., Fredenslund, A., Schiller, M., and Gmehling, J.: Vapor-liquid-equilibria by UNIFAC group contribution .5. Revision and extension, Ind. Eng. Chem. Res., 30, 2352-2355, 1991.

Hilal, S. H., Carreira, L. A., and Karickhoff, S. W.: Estimation of chemical reactivity parameters and physical properties of organic molecules using SPARC, in: Quantitative Treatments of Solute/Solvent Interactions, edited by: Politzer, P. and Murray, J. S., Elsevier, Amsterdam, 291-353, 1994.

Jensen, T., Fredenslund, A., and Rasmussen, P.: Pure component vapor pressures using UNIFAC group contribution, Ind. Eng. Chem. Fund., 20, 239-246, 1981.

Khetarpal, S. C., Lal, K., and Bhatnagar, H. L.: Thermodynamic studies on melting of aliphatic dicarboxylic acids, Indian J. Chem. A, 19, 516-519, 1980.

Kolská, Z., Ržika, V., and Gani, R.: Estimation of the enthalpy of vaporization and the entropy of vaporization for pure organic compounds at $298.15 \mathrm{~K}$ and at normal boiling temperature by a group contribution method, Ind. Eng. Chem. Res., 44, 84368454, 2005.

Lasdon, L. S., Waren, A., Jain, A., and Ratner, M.: Design and testing of a generalized reduced gradient code for nonlinear programming, ACM Trans. Math. Software, 4, 34-50, 1978.

Lee, S. C, Hung, H., Shiu, W.-Y., and Mackay, D.: Estimations of vapor pressure and activity coefficients in water and octanol for selected aromatic chemicals at $25^{\circ} \mathrm{C}$. Environ. Toxicol. Chem., 19, 2623-2630, 2000.

Lister, M. W.: Heats of organic reactions. X. Heats of bromination of cyclic olefins, J. Am. Chem. Soc., 63, 143-9, 1941.

Makar, P.: The estimation of organic gas vapour pressure, Atmos. Environ., 35, 961-974, 2001.

Meyer, E. F. and Hotz, R. D.: High-precision vapor-pressure data for eight organic compounds, J. Chem. Eng. Data, 18, 359-62, 1973.

Pankow, J. F.: An absorption model of gas/particle partitioning of organic compounds in the atmosphere, Atmos. Environ., 28, 185-188, 1994a.

Pankow, J. F.: An absorption model of the gas/particle partitioning involved in the formation of secondary organic aerosol, Atmos. Environ., 28, 189-193, 1994b.

Pankow, J. F.: A consideration of the role of gas/particle partitioning in the deposition of nicotine and other tobacco smoke compounds in the respiratory tract, Chem. Res. Toxicol., 14, 14651481, 2001.

Pankow, J. F.: Gas/particle partitioning of neutral and ionizing compounds to single and multi-phase aerosol particles, 1. Unified modeling framework, Atmos. Environ., 37, 3323-3333, 2003.

Pankow, J. F., Seinfeld, J. H., Asher, W. E., and Erdakos, G. B.: Modeling the formation of secondary organic aerosols. 1 . Theory and measurements for the $\alpha$-pinene/, $\beta$-pinene/, sabinene/, $\Delta^{3}$ carene/, and cyclohexene/ozone systems, Environ. Sci. Technol., 35, 1164-1172, 2001. See also Errata, Environ. Sci. Technol., 35, 3272, 2001.

Pankow, J. F., Tavakoli, A. D., Luo, W., and Isabelle, L. M.: Percent free-base nicotine in the tobacco smoke particulate matter of selected commercial and reference cigarettes, Chem. Res. Toxicol., 16, 1014-1018, 2003.

Pankow, J. F., Luo, W., Tavakoli, A. D., Chen, C., and Isabelle, L. M.: Delivery levels and behavior of 1,3-butadiene, acrylonitrile, benzene, and other toxic volatile organic compounds in mainstream tobacco smoke from two brands of commercial cigarettes, Chem. Res. Toxicol., 17, 805-813, 2004.

Rathbun, R. E.: Vapor pressures and gas-film coefficients for ketones, Chemosphere, 16, 69-78, 1987.

Reid, R. C., Prausnitz, J. M., and Poling, B. E.: The Properties of Gases and Liquids, 4th Edition, McGraw-Hill, New York, New York, 741 pp., 1987.

Roux, M. V., Temprado, M., and Chickos, J. S., Vaporization, fusion and sublimation enthalpies of the dicarboxylic acids from $\mathrm{C}_{4}$ to $\mathrm{C}_{14}$ and $\mathrm{C}_{16}$, J. Chem. Thermodyn., 37, 941-953, 2005.

Steele, W. V., Chirico, R. D., Knipmeyer, S. E., Nguyen, A., Smith, N. K., and Tasker, I. R.: Thermodynamic proper- 
ties and ideal-gas enthalpies of formation for cyclohexene, phthalan (2,5-dihydrobenzo-3,4-furan), isoxazole, octylamine, dioctylamine, trioctylamine, phenyl isocyanate, and 1,4,5,6tetrahydropyrimidine, J. Chem. Eng. Data, 41, 1269-1284, 1996.

Stull, D. R.: Vapor pressure of pure substances. Organic compounds, Ind. Eng. Chem., 39, 517-540, 1947.

Tao, Y. and McMurray, P. H.: Vapor pressures and surface free energies of C14-C18 monocar-boxylic acids and C5 and C6 dicarboxylic acids, Environ. Sci. Technol., 23, 1519-1523, 1989.
Tong, C., Blanco, M., Goddard III, W. A., and Seinfeld, J. H.: Thermodynamic properties of multifunctional oxygenates in atmospheric aerosols from quantum mechanics and molecular dynamics: Dicarboxylic acids, Environ. Sci. Technol., 38, 3941-3949, 2004.

Verevkin, S. P., Emel'yanenko, V. N., and Klamt, A.: Thermochemistry of chlorobenzenes and chlorophenols: Ambient temperature vapor pressures and enthalpies of phase transitions, J. Chem. Eng. Data, 52, 499-510, 2007. 